PPPL-3092

UC-420,427

COMPARISON OF THE CALCULATIONS OF THE STABILITY PROPERTIES

OF A SPECIFIC STELLARATOR EQUILIBRIUM WITH DIFFERENT MHD STABILITY CODES

BY

Y. NAKAMURA, T. MATSUMOTO, M. WAKATANI, ET AL.

APRIL 1995

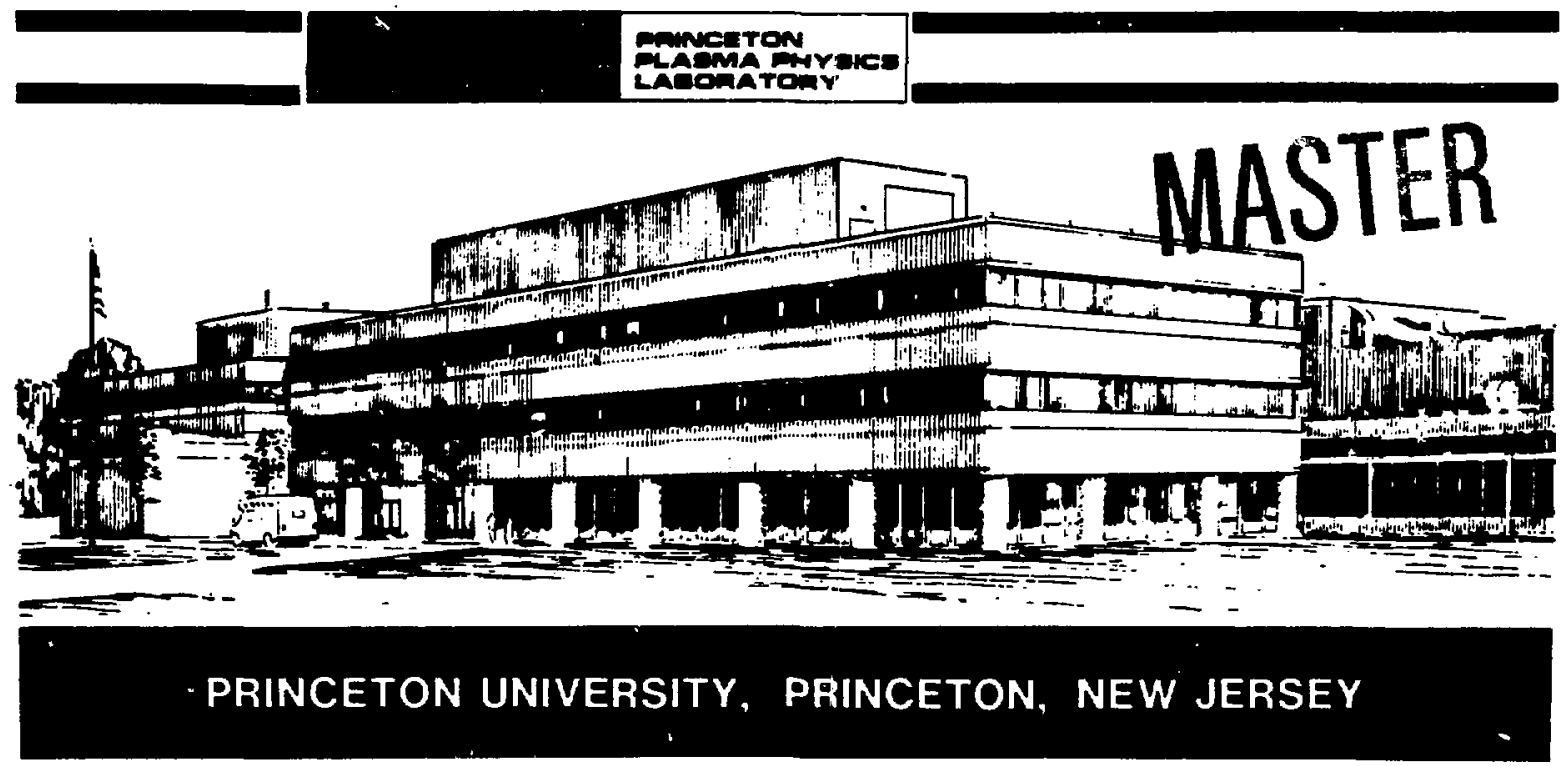




\section{NOTICE}

This report was prepared as an account of work sponsored by an agency of the United States Government. Neither the United States Government nor any agency thereof, nor any of their employees, makes any warranty, express or implied, or assumes any legai liability or responsibility for the accuracy, completeness, or usefulness of any information, apparatus, product, or process disclosed, or represents that its use would not infringe privately owned rights. Reference herein to any specific commercial produce, process, or service by trade name, trademark, manufacturer, or otherwise, does not necessarily constitute or imply its endorsement, recommendation, or favoring by the United States Government or any agency thereof. The views and opinions of authors expressed herein do not necessarily state or reflect those of the United States Govemment or any agency thereof.

\section{NOTICE}

This report has been reproduced from the best available copy. Available in paper copy and microfiche.

Number of pages in this report: 36

DOE and DOE contractors can obtain copies of this report from:

Office of Scientific and Technical Information

P.O. Box 62

Oak Ridge, TN 37831;

(615) 576-8401.

This report is publicly available from the:

National Technical Information Service

Department of Commerce

5285 Port Royal Road

Springfield, Virginia 22161

(703) $487-4650$ 


\title{
Comparison of the Calculations of the Stability Properties of a Specific Stellarator Equilibrium with Different MHD Stability Codes
}

\author{
Y. Nakamura, T. Matsumoto, M. Wakatani, \\ Plasma Physics Laboratory, Kyoto University
}
S. A.Galkin, V. V. Drozdov, A. A. Martynov, Yu. Yu. Poshekhonov, Keldysh Institute of Applied Mathematics, Moscow

\author{
K. Ichiguchi, \\ National Institute for Fusion Science, Nagoya \\ L. Garcia, \\ Universidad Carlos III de Madrid \\ B. A. Carreras, \\ Oak Ridge National Laboratory \\ C. Nührenberg (née Schwab) \\ Max-Planck-Institut für Plasmaphysik, Garching \\ W. A. Cooper, \\ Centre de Recherches en Physique des Plasmas, \\ Association Euratom - Confederation Suisse, \\ Ecole Polytechnique Fédérale de Lausanne \\ and \\ J. L. Johnson \\ Plasma Physics Laboratory, Princeton University \\ P. O. Box 451, Princeton, New Jersey 08543
}

\begin{abstract}
A particular configuration of the LHD stellarator with an unusually flat pressure profile has been chosen to be a test case for comparison of the MHD stability property predictions of different threedimensional and averaged codes for the purpose of code comparison and validation. In particular, two relatively localized instabilities, the fastest growing modes with toroidal mode number $n=2$ and $n=$ 3 were studied using several different codes, with the good agreement that has been found providing justification for the use of any of them for equilibria of the type considered.
\end{abstract}




\section{INTRODUCTION}

MHD equilibrium and stability properties of toroidal configurations are important for the design, study, and utilization of fusion devices. Many codes have been developed and much work has been done for the study of these properties in axisymmetric tokamak devices. The problem is not as simple in stellarators where the three-dimensional effects impose much more severe difficulties. Nevertheless, much progress has been made.

Considerable effort has been expended in the development of analytic and computational tools for the determination of three-dimensional equilibria. Two basic approaches have been employed: The early work utilized two-dimensional formulations which were obtained by using a -stellarator expansion ${ }^{\text {T1-5 }}$ or an averaging technique.$^{6-8}$ These codes have been employed in the design and interpretation of experiments and are still heing used. More recently, several fully three-dimensional codes have been developed, using energy minimization schemes ${ }^{9-15}$ as well as direct integration along the magnetic field lines. ${ }^{16,17}$ Most, but not all, of these codes are only useful for configurations in which the magnetic surfaces are well behaved, with any island structure that is present sufficiently localized that it presents no problem. Much effort has been expended to compare the predictions of these codes for configurations where magnetic islands do not pose a problem and the results have been very favorable. $3,4,10,11,18-20$ There is still a need for work on the determination of stellarator equilibria with islands and the comparison of results from different codes that can treat this problem.

The situation concerning codes for stability studies is not as complete. It is not obvious at first glance that there is a stability problem since at least some of these codes determine the equilibrium by finding the minimum potential energy of the system. Such equilibria should be stable by definition unless the chosen minimization fails to lead to the lowest energy state. In actual practice, most equilibrium configurations are prescribed to have periodic behavior over the magnetic field period associated with the geometric distortion of the configuration from axisymmetry or of the helical coils. Thus, the equilibrium should be stable with respect to any perturbation that does not destroy this helical periodicity. For this reason, stability is usually thought of as the question of whether relaxation of this periodicity constraint can lead to a lower energy state.

Considerable work has been done on the problem of stellarator stability. Since a typical stellarator has little or no net current, ore should expect that localized expressions, the Mercier criterion $D_{\mathrm{I}}<0$ for ideal modes, the analogous $D_{\mathrm{R}}<0$ criterion for resistive modes, [21] and ballooning mode considerations ${ }^{22}$ would provide sufficient guidance. These functions can be obtained by integrating along the magnetic field lines and can thus be detennined from the equilibrium code results. Comparison of resistive interchange mode criteria and ballooning instabilities has been done for the W7-AS stellarator, which has many of the features of a helias ${ }^{23}$ configuration, and the TJ-II heliac. ${ }^{24}$ This agreement can be understood by the fact that the resistive criterion differs from th: $=$ Mercier one primarily through the elimination of shear stabilization and that the plasma current in high- $\beta$ equilibria tends to reduce the local shear in regions of unfavorable curvature so that ballooning modes can grow even when the Mercier criterion is favorable. ${ }^{23-27}$ Since these studies only provide information about the forces local to a rational surface, it is useful to supplement them with studies of a more global character. This is being done, and some comparison of local and global mode stability criteria has already been reported. ${ }^{28}$

The treatment of more global modes is usually done by energy minimization techniques, and both twodimensional and three-dimensional formulations have been constructed. The first two-dimensional code of this type, STEP, ${ }^{29}$ was based on the steliarator expansion. It has been modified into a new improved code KSTEP. ${ }^{30-32}$ Several other codes ${ }^{11,33-36}$ are also based on this expansion. Other two-dimensional stability $\operatorname{codes}^{7,8,37,38}$ for three-dimensional configurations have been obtained with various averaging procedures. Initial value codes, ${ }^{39-41}$ in which the evolution of a system with the initial configuration having a small perturbation fiom equilibrium is followed, can be used to study the linear and nonlinear stability behavior. Indeed these codes can be used to construct equilibrium configurations by introducing a proper combination of resistivity and viscosity. More recently, some fully three-dimensional stability codes ${ }^{42-46}$ have been created to determine the linear eigenfunctions and eigenvalues of a Lagrangian munimization 
associated with small perturbations from equilibrium. A technique has also been constructed that makes it possible to examine the stability properties of an equilibriun that is calculated by the BETA code ${ }^{12}$ by carrying through a second series of minimizations with the imposition of additional constraints.

There has been some effort to compare the results of these codes in order to provide an understanding of how much confidence one could have in their predictions. Comparisons of the predictions of the stability properties of the ATF stellarator using the $\mathrm{STEP}^{29}$ and $\mathrm{FAR}^{35}$ codes showed very good agreement. ${ }^{11}$ In the same spirit, a comparison of the stability predictions of the STEP code, the helically invariant HERA code ${ }^{47}$ and the BETA code ${ }^{12}$ for a WENDELSTEIN VII-A model showed good agreement. ${ }^{48}$ Study of this same case with the TERPSICHORE code ${ }^{42}$ also gave a favorable comparison. ${ }^{49}$ Good agreement between the TERPSICHORE and CAS3D codes has been obtained in calculations of the global stability properties of a series of equilibria ranging from an $\ell=2$ conventional stellarator to a W7-X configuration. ${ }^{28,50}$ Although these different studies have been encouraging, it seems useful to carry through more comparison work in order to provide further validation of the models and to extend our understanding of the advantages and limitations of the different codes.

It is difficult to find configurations where all of the codes are easy to use. The two-dimensional models are based on the approximation that the rotational transform per helical field period is small, so that there must be a large number of periods. Thus, they should not be expected to work well for heliacs like TJ-II (Madrid) and H-1 (Canberra), or for the W7-AS and W7-X devices at Garching. On the other hand, it is difficult to justify extensive work on configurations like HELIOTRON $E$ which has nineteen field periods. We therefore chose our basic equilibrium to be the ten field period LHD stellarator ${ }^{51}$ that is being constructed at the National Institute for Fusion Science at Nagoya. Since it has been designed to have favorable confinement properties, a modification of it posed a difficult but not insurmountable problem for all of the codes.

The input for most of the stability codes can be generated by the VMEC equilibrium code. Some of the stability codes require input from their own equilibrium solvers which further complicates the comparison. They may have minor differences in the equilibrium properties, such as the exact shape of $t(\psi)$, which modify the modes and thus complicate the comparison. The differences in the formulations of the various models also makes the presentation of the results difficult. A major problem is that the definition of $\beta_{0}$, the ratio of the plasma pressure to the magnetic pressure at the magnetic axis, is not the same in the different codes because they employed different values of $B$ in the definition. $A$ second problem is that the codes do not all use the same function to label the surface variable. $A$ third is that the kintcic energy normalization used in defining the eigenvalue $\Lambda$ which is associated with the mode growth rate is also chosen differently. This makes it difficult to get exact comparisons. It was difficult to use exactly the same pressure distributions in carrying through the studies at the various laboratories. Thus, we have to compare results for somewhat different cases. There were two robust instabilities, one with a primarily $n=2$ toroidal mode number and the other with $n=3$. The dominant poloidal mode number for the $n=2$ mode was $n=3$ with the mode localized near where $t=2 / 3$ for values of $\beta_{0}$ up to about $7 \%$. Above this value the $m=4$ component becomes dominant. There was considerable difference in the unstable $n=3$ modes for the different pressure distributions. The $m=4$ mode is dominant for the case where $p=p_{I}$ whereas the $m=5$ mode is most important when $p=p_{\text {III }}$. Other more slowly growing modes were also observed.

We have used the KSTEP code ${ }^{30}$ as our basis for the comparison of the different codes because of convenience. This code comparison program originated at the Kyoto University Plasma Physics Laboratory and most of the work in compiling the results was done there. Since it was not possible to get all of the different codes to study exactly the same cases. it seemed to be worthwhile to exercise the KSTEP code, which has had significant use there, for all of the different pressure distributions to establish a common basis for the comparisons. We recognize that the results from this code are not necessarily better than, or even as good as, those from other codes.

We describe our LHD configuration in the next section. We then give short sections on the results from the different codes. We make a few comments about the comparison in the final section. 


\section{LHD EQUILIBRIUM CONFIGURATION}

The LHD stellarator ${ }^{51}$ has a major radius $R_{0}=3.9 \mathrm{~m}$. a set of $\ell=2, M=10$ helical coils with winding laws $\theta=(\ell / M) \phi+\alpha \sin (\ell / M) \phi$ and $\theta=(\ell / M) \phi+\alpha \sin (\ell / M) \phi+\pi$ where the helical modulation is $\alpha=0.1$, and six poloidal field coils that can provide dipole and quadrapole fields to shift and distort the plasma column. For the purpose of this comparison, we adjust the currents in these poloidal field coils to shift the vacuum field magnetic axis inward $15 \mathrm{~cm}$ from its nominal center. This is close to the standard configuration that the National Institute for Fusion Science intends to use for its basic operation and has an equilibrium configuration in which magnetic islands and ergodic regions are sufficiently small that they pose no problem.

We specify the plasma boundary to be

$$
\begin{aligned}
& R=\sum_{m, n} R_{m, n} \cos (m \theta-n M \phi) . \\
& Z=\sum_{m, n} Z_{m, n} \sin (m \theta-n M \phi),
\end{aligned}
$$

with the coefficients $R_{m, n}$ and $Z_{m, n}$ given in Table $I$. In actual operation one would expect to see a change in the shape and position of the boundary surface as the pressure is increased. This boundary modification is really an equilibrium problem and should not be introduced into this work since it would only complicate the stability code comparison. Furthermore, studies of LHD equilibria which are obtained with the VMEC code using a free boundary calculation with different prescriptions of the plasma-vacuurn interface show that the plasma shift and distortion improves the MHD stability properties, making the configuration even less useful for a code comparison. ${ }^{52}$ Thus. we keep this same boundary specification for determining the equilibria as we change the pressure.

For a typical stellarator application it is usual to prescribe the plasma pressure to be a parabolic function of the magnetic poloidal flux,

$$
p=p_{0}(1-\psi)^{2}
$$

with $\psi$ a normalized flux, and to have no net toroidal current on the magnetic surfaces. In most of the studies, we use the value of $\beta$ at the axis,

$$
\beta_{0}=2 p_{0} / B_{0}^{2} .
$$

with $B_{0}$ the magnitude of the vacuum field at the major radius $R_{0}$ which is not changed as $p_{0}$ is increased, to measure the pressure in the system.

We have examined this equilibrium with the KSTEP code ${ }^{30}$ and found it to be almost marginally stable even at relatively high values of $\beta_{0}{ }^{53}$ The growth rate that is calculated for these low- $n$ modes is so small (the eigenvalue $\Lambda=\omega^{2}\left[\rho R_{0}^{2} / B_{0}^{2}\right] \sim 10^{-5}$ ) that one should not expect to see an instability. This good physical behavior should have been expected since the LHD design was made for operation at relatively high values of $\beta$. However, the very small growth rates make tine configuration unsuitable for a comparison study.

On the other hand, relatively strong instabilities which are localized near an $t=2 / 3,3 / 4$, or $3 / 5$ resonant surface can be found for a more $\mathrm{H}$-mode-like pressure distribution with

$$
p=p_{1}(\psi) \equiv p_{0}\left(1-\psi^{2}\right)^{2} .
$$

again with $\psi$ a normalized poloidal flux. Therefore, we chose this distribution for some of the studies. We used

$$
p=p_{11}(\hat{\psi}) \equiv p_{0}\left(1-\hat{\psi}^{2}\right)^{2}
$$


with $\hat{\psi}$ the toroidal flux for some other ones. Since some of the codes work better with a pressure distribution with $p^{f}(0) \neq 0$, we have also considered a case with

$$
p=p_{I I I}(\hat{\psi}) \equiv \frac{p_{0}}{8}\left(\frac{V^{\prime}}{V^{\prime}(0)}\right)^{-2}\left[5\left(1-\hat{\psi}^{2}\right)^{2}+3(1-\hat{\psi})\right]
$$

with $V(\hat{\psi})$ the volume enclosed by the surface $\bar{\psi}$. The main difference between these flatter pressure profiles and the original parabolic one is that the region of large pressure gradient is shifted outwards. into a region where the magnetic field line curvature is strongly unfavorable.

The dependences of the pressure and the rotational transform on a normalized poloidal flux $\psi$ are shown for systems with these three pressure distributions with $\beta_{0}=4 \%$ in Figs. 1 and 2, respectively. It can be seen that the different models have strong similarities.

We considered two types of boundary conditions for the instability. Most of the work was directed at "fixed boundary" modes where the components of the displacement vector and the perturbed field normal to a magnetic surface vanish at the plasma boundary. In a few cases we also looked at "free boundary" modes where the nornal component of the perturbed nuagnetic field is continuous at the plasma surface and goes to zero at an outer wall or as we get far from the plasma.

\section{THE KSTEP CODE}

The KSTEP code is a straightforward introduction of the stellarator expansion ${ }^{1}$ into the formalism of the PEST $^{54}$ tokamak stability code. It works on a two-dimensional equilibrium which is obtained by averaging the results of a VMEC calculation ${ }^{14}$ over the toroidal angle $\phi$ to obtain averaged values of the contributions of the non-axially symmetric fields to the rotational transform and the nagnetic field line curvature. Although higher-order terms in the inverse aspect ratio are incorporated in the model and the code results have agreed well with other calculations. application of the code can only be justified rigorously in the large aspect ratio limit.

The assumption of large aspect ratio leads to the necessity of using the component of the displacement vector perpendicular to $B$ (which is in the $\nabla \phi$ direction in this order) to make $\xi$ divergence free in lowest order for an instability to exist. Then we can set

$$
\xi_{\perp}=\frac{R^{2}}{R_{0}^{2}} \nabla \phi \times \nabla \eta+\cdots
$$

This eliminates the fast magnetosonic waves from the problem, and our ability to adjust the component of $\xi$ parallel to $B$ can be used to remove the sound waves. Further minimization determines the higherorder components of $\xi$ and leads to a Lagrangian containing only the shear Alfvén waves, the effects of current along $B$, and a plasma expansion term;

$$
\mathcal{L}=\omega^{2} \int d \tau \frac{\rho}{R^{2}}|\nabla \eta|^{2}-\int d \tau\left\{\left|Q_{\perp}\right|^{2}+\frac{R_{0} B_{0} J \cdot B}{R^{2} B^{2}} Q_{\perp} \cdot \nabla \eta^{*}+\xi_{\perp} \cdot \nabla p \xi^{*} \cdot \nabla \Omega\right\}
$$

with

$$
Q_{\perp}=\nabla \phi \times \nabla\left[\left(R_{0} B_{0} \nabla \phi+\nabla \phi \times \nabla \psi\right) \cdot \nabla \eta\right]
$$

and

$$
\Omega=\frac{N}{2 \pi} \int_{0}^{2 \pi / N} d \phi \frac{R^{2}}{R_{0}^{2}}\left(1+\frac{\left|B^{\delta}(R, \phi, Z)\right|^{2}}{B_{0}^{2}}\right)
$$

This is solved by using a Fourier series decomposition in $\theta$ and $\phi$ and a sinple finite-element discretization in 4 . The weakness of the model is that modes with different toroidal mode numbers $n$ are decoupled, the effect of finite compressibility is eliminated, and the lowest-order displacement vector has no component along $\nabla \phi$. Since most stellarators have a reasonably large aspect ratio, these restrictious are usually well justified by the physics and these limitations rarely impose a problen. A major difficulty is that the 
magnetic axis should be nearly planar. making this code inapplicable for the study of heliac or helias devices in which the equilibrium contains a large $\ell=1$ helical component. We typically run the stability problem with a relatively low toroidal mode number. $n=1$ or 3 for example. choose a range of poloidal mode numbers sti $h$ as $-7 \leq m \leq 14$, and work with $k=769$ or more magnetic surfaces.

The fastest-growing "fixed boundary" $n=2$ mode for an equilibrium with the pressure given by Eq. (2) has an eigenvalue $\Lambda=\omega^{2}\left[\rho R_{0}^{2} / B_{0}^{2}\right]$ which varies with $\beta_{0}$ as shown in the first column of Table II and in Fig. 3. The Fourier components of the minimizing displacement normal to the magnetic surfaces are shown in Fig. $4 a$ for the $\beta_{0}=4 \%$ case. Convergence studies in which the number of poloidal modes is changed have shown little variation in earlier studies. ${ }^{55}$ so modification of the range of poloidal modes is of little concern. On the other hand, the results are sensitive to the number of surfaces that are considered when the eigenfunction is extremely localized at the resonant surface and we have not carried through a proper study.

The eigenvalues for the "fixed boundary" $n=2$ mode in the configuration with $p$ given by Eq. (3) are in the first column of Table III and in Fig. 5, and the eigenfunction for the $\beta_{0}=4 \%$ case is in Fig. $6 a$. Relaxation to a "free boundary" condition where the normal component of the perturbed magnetic field is forced to vanish at $r(\psi)=1.3 a_{p}$, far from the plasma surface, leads to the eigenvalues in the third column of Table III, which are shown in Fig. 7. The eigenfunction for a case with $\beta_{0}=7 \%$ is shown in Fig. $8 a$. It is worth mentioning that there is very little difference between the "fixed" and "free" boundary eigenvalues when $\beta_{0}=4 \%$.

Results for the "fixed boundary" $n=3$ mode with the pressure distribution of Eq. (2) are in the first colunun of Table IV and in Figs. 9 and 10a. Similar results for the $n=3$ node in the system with $p$ given by Eq. (3) are in the first column of Table $V$ and in Figs. 11 and $12 a$.

\section{THE TWIST CODE}

The TWIST code is based on a relatively new approach ${ }^{37,56}$ for constructing approximate models for MHD equilibrium and stability. It works in conjunction with the three-dimensional and two-dimensional equilibrium codes POLAR-3D code ${ }^{57}$ and POLAR-2D. ${ }^{58}$ The key point of this variational formalisn can be briefly described as follows: We start with a prescribed vacuum field or finte- $\beta$ three-dimensional equilibriun. a so-called background configuration which can be obtained either analytically or numerically. Then a formal functional with two-diniensional coefficients which approximates the plasma potential energy.

$$
\int_{\mathrm{n}_{\mathrm{P}}}\left[\frac{B^{2}}{2}+\frac{p}{\gamma-1}\right] d^{3} r
$$

for configurawons close to the background one can easily be constructed. First and second variations of this functional consistently lead to approximate MHD equilibrium and stability models. This procedure is done in such a way that it gives exact models for plasmas with planar, axial, or helical symmetry. Moreover, it gives an exact equilibrium description for the background plasma and stability criteria for modes with toroidal mode numbers $n$ which are decoupled from the equilibrium quantities. The coefficients of these two-dimensional approximated functionals are determined by only the metric tensor of the straight magnetic field line coordinate system of the background configuration and the freedom in its choice can be used to get the best (from one or another point of view) approximation.

One of the guiding elements in this formalism is that construction of two-dimensional necessary and sufficient stability criteria as well as extension to a fully threedimensional model would be straightforward.

The approach gives in a natural way a nontraditional representation of the potential energy associated with small perturbations

$$
\begin{aligned}
& W(\delta s, \delta \lambda)=\frac{1}{2} \int_{\Omega_{p}}\left\{Q^{2}+\delta s(J \cdot \nabla \delta \lambda)-\delta \lambda(J \cdot \nabla \delta s)\right. \\
&\left.+(J \cdot(\nabla \times D) \times \hat{e})(\delta s)^{2}+(\nabla p \cdot \hat{e}) \nabla \cdot\left(\hat{e}(\delta s)^{2}\right)\right\} d^{3} r
\end{aligned}
$$


with

$$
\xi=-\delta s \frac{D \times B}{B^{2}}-\delta \lambda \frac{B \times \nabla s}{B^{2}}-\mu \frac{B}{B^{2}}
$$

where

$$
\begin{aligned}
\boldsymbol{Q}=\nabla(\xi \times B)= & -\nabla \times(\delta \lambda \nabla s-\delta s D), \\
D=\Phi^{\prime} \nabla \theta+\Phi^{\prime} \nabla \zeta, & B=\nabla s \times D, \\
\hat{\boldsymbol{\epsilon}}= & \nabla s /|\nabla s|^{2}, \\
\delta s= & -(\xi \cdot \nabla s) . \\
\delta \lambda= & -(\xi \cdot D) .
\end{aligned}
$$

and $(s, \theta, \zeta)$ is an arbitrary straight magnetic field line coordinate system for the configuration that is being determined. We have dropped the plasina compression term $\gamma p(\nabla \cdot \xi)^{2}$, thus eliminating slow magnetosonic waves, and chosen $\mu=0$ in the kinetic energy. Therefore we actually overestimate the linear growth rate of the instabilities.

The attractive feature of this functional $W$ representation is that in a straight magnetic field line coordinate system it contains as coefficients only seven functions related to the metric tensor: $g_{i, j} / \sqrt{g}$ appears in the first term and $\sqrt{g}$ in the others. This is convenient for spectral methods and our experience has shown that it can improve convergence properties.

In the two-dimensional stability model of the TWIST code we take into account only the $n=0$ harmonics of the metric tensor. It is clear that, for a single mode with $\xi=\xi(s, \theta) e^{i n \zeta}$ which is decoupled from the equilibrium, this gives an exact stability criterion. In fact, we could and did implement this criterion by deriving the metric tensor components approximately: first computing the background configuration and then increasing $\beta$ in the frame of the two-dimensional approximate equilibrium nodel.

It is useful to note that the results from the TWIST code show the threedimensional character of the perturbed solution directly since the full threedimensional geometry is built into the metric. Similar representations can be obtained from the other two-dimensional codes since we know the minimizing displacement and can evaluate

$$
\begin{aligned}
\Psi(\boldsymbol{r}+\xi) & =\Psi_{0}(\boldsymbol{r}+\xi)+\Psi_{\delta}(\mathbf{r}+\xi) \\
& =\Psi_{0}(\boldsymbol{r})+\xi \cdot \nabla \Psi_{0}(\boldsymbol{r})+\Psi_{\delta}(\boldsymbol{r})
\end{aligned}
$$

In the TWIST code Fourier decomposition is used in the poloidal and toroidal directions and special finite-difference schemes ${ }^{58}$ (close to the hybrid finite-elements of the ERATO code ${ }^{60}$ ) were employed in the radial direction. Calculation could be done both for internal modes and for external ones where the vacuum region is treated as if it were zero-current pressureless plasma. The code has been tested extensively for axisymmetric equilibrium configurations and has shown good convergence properties. This study is the first najor comparison with other stellarator stability codes.

Application of this code was made to the LHD configuration with the pressure given by Eq. (2). The equilibrium was calculated with the POLAR-2D code co $^{59}$ a $64 \times 64$ mesh using an interpolation of the straight magnetic field line metric tensor of the vacuum configuration as input. This vacuum field background configuration had been computed with the POLAR-3D code ${ }^{57}$ on a rather rough mesh $24 \times 24 \times 24$. This procedure was chosen because of restrictions in coniputer resources for the actual three-dimensional equilibrium calculations. On the other hand, the results that were obtained allow us to see the accuracy of the approximate models that are obtained even when the background threedinensional equilibrium configuration is far from the finite $\beta$ one. Using a background configuration that is closer to the desired one and taking into account more than one of the largest toroidal components in 
the Fourier representation of the metric tensor should inprove the comparison results. The convergence studies showed that $\mathbf{9}$ poloidal harmonics and up to $\mathbf{9 0}$ radial mesh points are sufficient for calculating with an accuracy of about $1 \%$. The eigenvalues associated with the fastest growing $\boldsymbol{n}=\mathbf{2}$ instability are tabulated in the second column of Table II and shown in Fig. 3 and the eigenfunction for the $\beta_{0}=4.2 \%$ case is in Fig. $4 b$. The results for the $n=3$ instability with this pressure distribution are given in the second column of Table IV and in Figs. 9 and $10 b$.

The free boundary case is approached in this code by considering an outer boundary a factor of 4 larger than the plasina-vacuum interface and in general has a much larger growth rate. For an $n=1$ mode the value of $\Lambda$ increases from $8.73 \times 10^{-5}$ to $1.727 \times 10^{-2}$ for the $\beta_{0}=6.6 \%$ case.

\section{THE RESORM CODE}

The RESORM code $\mathrm{e}^{36}$ is a two-dimensional initial value code which is based on the "Stellarator Expansion". The basic equations of the code are the linearized inconpressible reduced MHD equations.

$$
\begin{aligned}
\frac{\partial A}{\partial t} & =-\left(\frac{R}{R_{0}}\right)^{2} B \cdot \nabla \Phi, \\
\rho \frac{\partial \Delta . \Phi}{\partial t} & =-B \cdot \nabla \Delta_{.} A+\nabla A \times \nabla J_{\text {deq }} \cdot \nabla \phi+R_{0}^{2} \nabla \Omega \times \nabla p \cdot \nabla \phi \\
\frac{\partial p}{\partial t} & =\left(\frac{R}{R_{0}}\right)^{2} \nabla \Phi \times \nabla p_{\mathrm{eq}} \cdot \nabla \phi
\end{aligned}
$$

for the three scalar functions $A$, the poloidal magnetic flux divided by $2 \pi, \Phi$, the velocity stream function, and $p$, the plasna pressure. Here the magnetic differential operator is

$$
B \cdot \nabla=\frac{R_{0} B_{0}}{R^{2}} \frac{\partial}{\partial \phi}-\nabla \Psi_{\mathrm{eq}} \times \nabla \phi \cdot \nabla,
$$

and $\Psi_{\text {eq }}, J_{\text {teq }}$ and $P_{\text {eq }}$ denote the equilibrium poloidal flux, the toroidal component of the equilibrium current density and the equilibrium pressure, respectively. The averaged curvature of the magnetic field line $\Omega$ is given by Eq. ( 7 ) and the operator $\Delta$. is defined by

$$
\Delta_{*}=R^{2} \nabla_{\perp} \cdot\left(\frac{\nabla_{\perp}}{R^{2}}\right), \quad \nabla_{\perp}=\nabla-\nabla \phi \frac{\partial}{\partial \phi} .
$$

The relation between the stream function and the perturbed plasma velocity perpendicular to the magnetic field $\mathbf{v}_{\perp}$ is given by

$$
\mathbf{v}_{\perp}=\left(\frac{R}{R_{0}}\right)^{2} \nabla \Phi \times \nabla \phi
$$

These three-field equations differ from the reduced MHD equations for stellarators that were derived by Strauss. ${ }^{34}$ by keeping higher order toroidal corrections through the factor $R / R_{0}$.

Since they employ the same physics model and approximations that the KSTEP code does, the RESORM code can examine the stability of $3 \mathrm{D}$ equilibria by utilizing the interface code between the VMEC code ${ }^{14}$ and the KSTEP stability code. ${ }^{30}$ The normalization of the growtl rate of the perturbation is also the same as the one in the KSTEP code.

The eigenvalues for the $n=2$ case where $p$ is given by Eq. (2) are tabulated in the third colunin of Table 11 and shown in Fig. 3 and $4 b$. The eigenvalues and eigenfunctions for the $n=3$ case where $p$ is given by Eq. (4) are in the second column of Table V and in Figs. 11 and $12 b$. 


\section{THE CHAFAR CODE}

The CHAFAR code ${ }^{38}$ is also an initial value code based on the "Stellarator Expansion." The major innovation in this code is the application of the averaging in a straight magnetic field line (Boozer) coordinate system associated with the exact three-dimensional finite- $\beta$ equilibrium. Thus the code can be used for treatment of systems like heliacs and helias in which the magnetic axis is strongly non-planar. It utilizes the standard low- $\beta$, small non-axisymmetry expansion and introduces a stream function for the perturbed velocity to eliminate the fast and slow magnetosonic waves. Although the derivation is based on the standard ordering of the stellarator expansion, the geometrical terns are taken exactly from the equilibrium. In particular, the displacement vector component orthogonal to $B$ is

$$
\xi_{\perp}=\frac{R_{0}}{\mathcal{D}} \nabla \phi \times \nabla \eta
$$

and the field line curvature term is given by $\partial \Omega / \partial \rho$, where

$$
\Omega=\frac{N}{2 \pi} \int_{0}^{2 \pi / N} \frac{R_{0}}{\mathcal{D}} d \phi
$$

$p=\left(2 \hat{\psi} / B_{0}\right)^{\frac{1}{2}}$ with $\hat{\psi}$ the toroidal flux divided by $2 \pi, \mathcal{D}$ is the inverse Jacobian of the transformation to Boozer coordinates, ${ }^{38}$ and $\phi$ is the toroidal angle-like Boozer coordinate. The expressions (13) and (14) correspond to the expressions (5) and (7) in the stellarator expansion formulation of the KSTEP code. The differences between these expressions lead to a change in the effective curvature. The model has been implemented into the initial value incompressible MHD code FAR $^{35}$ which utilizes a fully implicit scheme that allows a very fast deternination of the linear growth rate. The perturbed quantities are represented as Fourier series in $\theta$ and $\phi$, and a finite difference scheme is used for the variable $\rho$.

We have carried through the calculation for the LHD configuration with the pressure given by Eq. (2). looking at the $n=2$ mode and using 7 Fourjer components in $\theta$. Convergence studies have been carried out in the number of computational surfaces, going from 200 to 800 . The converged eigenvalues are tabulated in the fourth column of Table II and plotted in Fig. 3. The eigenvalue $\Lambda$ is approximately ten times smaller than those obtained with the KSTEP and TWIST codes, which is due to the change in the effective curvature which was described above. The normal component of the eigenfunction is given in Fig. $4 d$ for the case where $\beta_{0}=4 \%$.

\section{THE TERPSICHORE CODE}

The TERPSICHORE code42.44,40 was constructed by the group at Ecole Polytechnique Fédérale de Lausanne in cooperation with nembers of the Max-Planck-Institut für Plasmaphysik at Garching. It extremizes the Lagrangian associated with the linear behavior of small displacements from equilibrium,

$$
\begin{gathered}
\mathcal{L}=\omega^{2} \int d \tau p|\xi|^{2}-W, \\
W=\frac{1}{2} \int_{p} d \tau\left[|C|^{2}-\mathcal{A}(\xi \cdot \nabla s)^{2}+\gamma p(\nabla \cdot \xi)^{2}\right], \\
C=\nabla \times(\xi \times B)+\frac{J \times \nabla s}{|\nabla s|^{2}} \xi \cdot \nabla s, \\
\mathcal{A}=2\left[\left.\nabla s\right|^{-4}(J \times \nabla s) \cdot(B \cdot \nabla \mid \nabla s .\right.
\end{gathered}
$$

with

$$
\xi=\sqrt{g} \xi^{s} \nabla \theta \times \nabla \phi+\eta \frac{B \times \nabla s}{B^{2}}+\left(\frac{J(s)}{B^{2} \Phi^{\prime}(s)} \eta-\mu\right) B
$$


where $\theta$ and $\phi$ are the poloidal and toroidal angles in Boouzer coordinates, $s$ is an arbitrary magnetic surface label, $\sqrt{g}$ is the Jacobian. $J(s)$ is the toroidal current inside the surface $s$, and $\Phi$ is the toroidal flux. Since the kinetic energy term in Eq. (15) does not affect the value of $\beta_{0}$ at which the configuration becomes unstable, it was simplified as in the PEST-2 tokaniak stability code fornulatiori ${ }^{61}$ for computational efficiency. The component $\mu$ is chosen to make $\nabla \cdot \xi=0$ to remove the term associated with plasma compressibility (the slow magnetosonic wave). The comporents $\xi^{s}$ and $\eta$ are Fourier decomposed in $\theta$ and $\phi$, and a finite hybrid element radial discretization scheme is applied. A careful choice of the basis functions that are used ${ }^{62}$ has improved the convergence properties of the code over that observed in the original ERATO code. ${ }^{\text {c0 }}$ The code has been well optinized so that it is fast: an earlier version haw won a competition sponsored by Cray Research. Inc. for well construcied codes.

A distinct advantage of tluree-dinensional codes over two-dimensional ones is that the effect of toroidal mode coupling can be studied. The effect can be seen even for the LHD configuration that we study here.

We used the pressure distribution of Eq. (3) for this study. The converged fixed boundary" eigenvalues for the fastest growing $n=2$ mode are given in tr- second column of Table III and in Fig. 5 . The eigenfunction for $\beta_{0}=4 \%$ is in Fig. 6b. The corresponding "free boundary" eigenvalues and eigenfunctions are given in Table III and Figs. $i$ and $8 b$.

\section{THE CAS3D CODE}

The CAS3D series of codes ${ }^{\mathbf{4 3 . 4 5 , 4 6}}$ was constructed at the Max-Planck-Institut für Plasmaphysik at Garching to study the global MHD stability properties of helias type stellarators. It is a fully threedinensional code which utilizes a $\delta W$ formulation to investigate the behavior of small perturbations from an equilibrium configuration which is obtained vith the VMEC code. ${ }^{14}$ The potential energy is again given by Eq. (16). As in most of the models. it is clear that the last term in Eq. (16). corresponding to slow magnetosonic waves (plasna compression), is always stabilizing and does not affect the value of $\beta$ at which the system is marginal. The component of $\boldsymbol{\xi}$ along $\boldsymbol{B}$ can be and is chosen to eliminate this term. In a similar manner. the component of $\boldsymbol{C}$ along $\boldsymbol{B}$ which is associated with the fast magnetosonic wave (field compression) is also stabilizing. Studies of the contributions from the various ternts shows that the ninimizing perturbation always makes this term extremely small. Thus, although the code can be run keeping these fast magnetosonic modes, it is desirable to determine the component of $\xi$ in the $\boldsymbol{B} \times \nabla s$ direction as a function of $\boldsymbol{\xi} \cdot \nabla s$ analytically to eliminate this term. This is easily accomplished since we use Fourier decomposition in the poloidal and toroidal directions and finite elementis in the $\nabla$ s direction to represent the perturbations and derivatives of the surface components of $\xi$ with respect to $s$ do not enter the expression for $\delta W$. Since the actual growth rates are not inportant, we use only the $\xi \cdot \nabla s$ component of the perturbation in the kinetic energy term.

The CAS3D code also has the distinct advantage over two-dinensional codes that the effect of toroidal mode coupling can be studied. It is obvious that only certain toroidal Fourier lıarmonics are coupled by the equilibrium properties so that mode fanilies exist, each characterized by a dominant $n=1, n=2$. etc. component, and that the different fanilies can be studied separately. This coupling is particularly important for configurations with a small number of field periods. The effect can be seen even for the LHD configuration that we study here.

We have used this code to study the LHD configuration with the pressure distribution given by Eq. (4) for the mode with $n=3$ and its asssciated toroidal harmonics. The eigenvalues are given as functions of $\beta_{0}$ in the third column of Table $Y$ and in Fig. 11, and the radial component of the eigenfunction is given in Fig. $12 \mathrm{c}$ for the case where $\beta_{0}=4 \%$. When only one toroidal harmonic is retained, the eigenmode is stabilized and $\Lambda$ changes from $-2.38 \times 10^{-3}$ to $-6.8 \times 10^{-4}$ for this case. 


\section{DISCUSSION}

It is difficult to carry through a study of this type where the authors are located in different places and have different limitations and problems with their codes. For this reason, we were not able to study exacily the same equilibrium or to produce results that have the same basis. Indeed, the different codes did not use the same kinetic energy normalization or definition of $\beta_{0}$ and treated the behavior of the fast and slow magnetosonic waves ir somewhat different manners. We have been able to carry through the comparison of two or more codes for each pressure distribution that was used so that some understanding of the output of each code has been obtained. We should be pleased to see that all of the codes found the same relatively localized $n=2$ and $n=3$ modes near where they should be expected to be the most unstable modes, with the eigenvalues $\Lambda$ having the same behavior as $\beta_{0}$ is changed. The behaviors of the displacement vector in the $\nabla s$ direction found by the different codes are also sinilar. It is useful to observe that the codes show the same change in behavior of the mode as $\beta_{0}$ is increased. For example, with the $p_{I}$ pressure distribution, the $n=2$ mode shows a strong nonmonotonicity (see Fig. 3 ). It has a strong $m=3$ component which peaks at $\beta_{0} \approx 7 \%$ and then falls off. An $m=4$ dominated mode starts growing as $\beta_{0}$ is increased to even higher values.

We conclude from this study that all of the tools that have been developed for stellarator stability studies are capable of treating this LHD stellarator model accurately. This is a strong test of the codes since the standard LHD equilibrium is stable, or close to stable, so that a pressure distribution with $\nabla p$ localized to the outer region had to be assumed to even find an unstable mode. It should also be remarked that other codes which were not treated in this study have been compared to some of the ones which were exercised here. Thus, the tools that are available for study of stellarator stability are quite extensive.

It is obvious that the different codes are useful for different applications. For example, the KSTEP and RESORM codes can not be used for heliac and helias type configurations where the magnetic axis is strongly nonplanar. On the other hand, these codes are particularly useful for treatment of configurations like HELIOTRON E, ATF, and LHD which have many field periods.The TWIST, CHAFAR, CAS3D, and TERPSICHORE cades are well adapted for a study of them, although the small number of helical field periods in these devices makes the averaging to a 2-D model somewhat suspect. It was noted earlier ${ }^{28,32.46,63}$ that the behavior of the low- $n$ modes is usually similar to that of the high- $n$ modes so that one slould expect to see some correspondence between the ejgenvalues and the Mercier criterion, $D_{1}$ or resistive interchange criterion, $D_{\mathrm{R}}$. The same conclusion tends to be true for ballooning modes although these modes may be especially serious because of the destruction of local shear by the plasma currents in high- $\beta$ equilibria. ${ }^{23-27}$ This differs from tokamak studies where the toroidal current provides a strong driving mechanism for global modes making them tend to be the most limiting instabilities.

We should emphasize again that our choice of an LHD model for this comparison study should not be taken to imply that this system will suffer from poor MHD stability properties. Indeed, in our stability studies we found that the standard operating configuration is stable, or extremely close to stable. We therefore had to adopt an unusually flat pressure profile in order to push the large pressure gradient into a region of unfavorable magnetic field line curvature so that an instable mode could grow. We used a "fixed boundary" model for the plasma, in which the shape and position of the plasma-vacuum interface was preserved as $\beta_{0}$ was increased. We should note again that "free-boundary" equilibrium calculations have shown ${ }^{49}$ that the finite- $\beta$ alterations of the plasma surface should improve the system's stability properties over those of our model.

\section{DISCLAIMER}

This report was prepared as an account of work sponsored by an agency of the United State Government. Neither the United States Government nor any agency thereof, nor any of their employees, makes any warranty, express or implied, or assumes any legal liability or responibility for the accuracy, completeness, or usefulness of any information, apparatus, product, or process disclosed, or represents that its use would not infringe privately owned rights. Reference herein to any specific commercial product, process, or service by trade name, trademark, manufacturer, or otherwise does not necessarily constitute or imply its endorsement, reconmendation, or favoring by the United States Government or any agency tbereof. The views and opinions of authors expressed herein do not necessarily state or reflect those of the United States Government or any agency thereor. 


\section{ACKNOWLEGEMENTS}

W. A. Cooper was supported by the Fonds National Suisse de la Recherche Scientifique. J. L. Johnson was supported by the Unjted States Department of Energy under Contract \#DE - AC02 - 76-CHO 3073 with Princeton University. He was supported for two visits to Kyoto University to work on this problem and wishes to express his appreciation to the Japanese Ministry of Education, Science, and Culture for providing a financial grant to make his first visit possible and to the Japanese Society for the Promotion of Science for providing for the second one. He thanks his hosts at the Kyoto University Plasma Physics Laboratory for the kind and helpful treatment that they gave him on both accasions. We wish to thank Dr. S. P. Hirshman for the use of his VMEC code, and to Professor V. D. Shafranov, Professor L. M. Degtyarev, Profeseor F. Troyon, Dr. J. Nührenberg, Dr. J. Todoroki, and others who made this collaboration possible. We are indebted to Dr. D. V. Anderson for much useful interaction establishing this test case and in the use of the TERPSICHORE code for providing preliminary results. 


\section{References}

${ }^{1}$ J. M. Greene and J. L. Johnson, Phys. Fluids 4, 875 (1961)

${ }^{2}$ G. Anania, J. L. Johnson, and K. E. Weimer, Phys. Fluids 26, 2210 (1981)

${ }^{3}$ V. E. Lynch, B. A. Carreras, L. A. Charlton, T. C. Hender, L. Garcia, H. R. Hicks, and J. A. Holmes, J. Comput. Phys. 66, 411 (1986)

${ }^{4}$ T. C. Hender and B. A. Carreras, Phys. Fluids 27, 2101 (1984)

${ }^{5}$ V. D. Pustovitov, V. D. Shafranov, L. I. Zakharov, L. M. Degtyarev, V. V. Drozdov, S. Yu. Medvedev, Yu. Yu. Poshekhonov, and M. I. Mikhajlov, in Plasma Physics and Controlled Nuclear Fusion Research, 1982 (International Atomic Evergy Agency, Vienna, 1983) volume II, page 541

'L. M. Kovrizhnykh and S. V. Shchepetov, Soviet J. Plasma Phys. 6, 533 (1980)

7J. Todoroki, J. Phys. Soc. Japan 56, 128 (1987)

${ }^{8}$ J. Todoroki, J. Phys. Soc. Japan 58, 3979 (1989)

${ }^{9}$ R. Chodura and A. Schlüter, J. Comput. Phys., 41, 68 (1981)

${ }^{10}$ T. C. Hender, B. A. Carreras, L. Garcia, J. A Rome, and V. E. Lynch, J. Comput. Phys. 60, 76 (1985)

${ }^{11}$ T. C. Hender, B. A. Carreras, L. A. Charlton, L. Garcia, H. R. Hicks, J. A. Holmes, and V. E. Lynch. Nuclear Fusion 25, 1463 (1985)

${ }^{12}$ F. Bauer, O. Betancourt, and P. Garabedian, Magnetohydrodynamic Equilibrium and Stability of Stellarators (Springer-Verlag, New York, 1984)

${ }^{13}$ O. Betancourt, Commun. Pure Appl. Math 41, 551 (1988)

${ }^{14}$ S. P. Hirshman, W. I. vanRij, and P, Merkel, Comput. Phys. Commun. 43, 143 (1986)

${ }^{15}$ M. Taylor, J. Comput. Phys. 110. 407 (1994)

${ }^{16}$ A. Reiman and H. S. Greenside, Comput. Phys. Commun. 43، 157 (1986)

${ }^{17} \mathrm{~J}$. Kisslinger and H. Wobig, in Twelfth European Conference on Controlled Fusion and Plasma Physics (Budapest, 1985) vol. 9A, pt.1, p. 453

${ }^{18}$ G. Rewoldt, J. L. Johnson, J. A. Holmes, in Sherwood Meeting on Theoretical Aspects of Controlled Fusion Research (Arlington, 1983), paper 1P18

${ }^{19}$ B. A. Carneras, L. A. Charlton, T. C. Hender, H. R. Hicks, J. A. Holmes, V. E. Lynch, L. Garcia, J. H. Harris, and B. F. Masden, Phys. Fluids 26, 3569 (1983)

${ }^{20}$ J. L. Johnson, D. A. Monticello, A. H. Reiman, A. Salas, A. L. Fraguas, and S. P. Hirshman, Comput. Phys. Commun. 77, 1 (1993)

${ }^{21}$ A. H. Glasser, J. M. Greene, and J. L. Johnson, Phys. Fluids 18, 875 (1975)

${ }^{22}$ D. Correa-Restrepo, Z. Naturforsch. 33a, 789 (1978)

${ }^{23}$ J. Nührenberg and R. Zille, Phys. Letters 114A, 129 (1986)

${ }^{24}$ J. Nührenberg and R. Zille, in Theory of Fusion Plasmas, Proceedings of the Varenna Workshop (Editrice Compositori, Societá Italiana di Fisica, 1987). 
${ }^{25}$ W. A. Cooper, Y. Nakamura, M. Wakatani. R. Gruber, S. Merazzi, D. V. Anderson, and U. Schwenn, in Proceedings of the Nineteenth European Physics Society Conference on Controlled Fusion and Plasma Physics (Innsbruck 1992), vol. 16C, pt. 1, p. 557.

${ }^{28}$ W. A. Cooper and H. J. Gardner, Nucl. Fusion 34, 729 (1994)

${ }^{27}$ N. Nakajima, Y. Nakamura, M. Wakatani, and M. Okamoto, private communication

28 J. Nührenberg, P. Merkel, C. Schwab, U. Schwenn, A. Cooper, T. Hayashi, S. P. Hirshman. J. L. Johnson, D. A. Monticello, and A. H. Reiman, Plasma Phys. Control. Fusion 35 B115 (1993)

${ }^{29} \mathrm{G}$. Anania and J. L. Johnson, Phys. Fluids 26, 3070 (1983)

${ }^{30}$ Y. Nakamura, K. Ichiguchi, M. Wakatani, and J. L. Johnson, J. Phys. Soc. Japan 58, 3157 (1989)

${ }^{31}$ Y. Nakamura, M. Wakatani, and K. Ichiguchi, Journal of Plasma and Fusion Research (formerly Kakuyugo Kenkyu) 69, 41 (1993)

${ }^{32}$ Y. Nakamura, K. Ichiguchi, M. Wakatani, B. A. Carreras, N. Dominguez, J. N. LeBoeuf, V. E. Lynch. J. L. Johnson, and G. Rewoldt, in Theory of Fusion Plasmas (J. Vaclavic, F. Troyon, and E. Sindoni, Eds., ISPP-6 Piere Caldirola, SIF Bologna, 1990), p. 677

${ }^{33}$ V. E. Lynch, B. A. Carreras, H. R. Hicks, J. A. Holmes, and L. Garcia, Comput. Phys. Commun. 24, $465(1981)$

${ }^{34}$ H. R. Strauss, Plasma Phys. 22, 733 (1980)

${ }^{35}$ L. A. Charlton, J. A. Holmes, H. R. Hicks, V. E. Lynch, and B. A. Carreras, J. Comput. Phys. 63, 107 (1986)

${ }^{36}$ K. Ichiguchi, Y. Nakamura, and M. Wakatani, Nuclear Fusion 31, 2673 (1991)

${ }^{37}$ S. A. Galkin, V. V. Drozdov, and A. A. Martinov, Keldysh Institute of Applied Mathematics preprint KIAM, No. 52 (1991)

${ }^{38}$ L. Garcia, B. A. Carreras, N. Dominguez, J. N. Leboeuf and V. E. Lynch, Phys. Fluids B2, 2162 (1990)

${ }^{39}$ W. Park, D. A. Monticello, H. R. Strauss, and J. Manickam, Phys. Fluids 29, 1131 (1986)

${ }^{40}$ R. Izzo, D. A. Monticello, H. R. Strauss, W. Park, J. Manickam. R. C. Grimm, and J. DeLucia, Phys. Fluids 26, 3066 (1983)

${ }^{41}$ T. Hayashi, T. Sato, and A. Takei. Phys. Fluids B2, 329 (1990)

${ }^{42}$ D. V. Anderson, W. A. Cooper, U. Schwenn, and R. Gruber, in Proc. of the Joint Varenna-Lausanne International Workshop on Theury of Fusion Plasmas (Editrice Compositori, Bologna, 1988) p. 93

${ }^{43} \mathrm{C}$. Schwab, in Proc. of the Joint Varenna-Lausanne International Workshop on Theory of Fusion Plasmas (Editrice Compositori, Bologna. 1988) p. 52

${ }^{44}$ W. A. Cooper, G. Y. Fu. R. Gruber, S. Morazai, U. Schwenn. and D. V. Anderson, in Theory of Fusion Plosmos (J. Vaclavic, F. Troyon, and E. Sindoni, Eds., ISPP-6 Piere Caldirola, SIF Bologna, 1990), p. 655

${ }^{45} \mathrm{C}$. Schwab, in Theory of Fusion Plasmes (J. Vaclavic, F. Troyon, and E. Sindoni, Eds., ISPP-6 Piere Caldirola, SIF Bologna, 1990), p. 686

${ }^{46}$ C. Schwab, Phys. Fluids B5, 3195 (1993)

${ }^{47}$ R. Gruber, S. Semenzato, F. Troyon, T. Tsunematsu, W. Kerner, and W. Schneider, Comput. Phys. Commun. 24, 363 (1981) 
${ }^{48}$ F. Herrnegger, P. Merkel, and J. L. Johnson, J. Comput. Phys. 66, 445 (1986)

${ }^{49}$ G. Y. Fu, W. A. Cooper, R. Gruber, U. Schwenn and D. V. Anderson, Phys. Fluids B4, 1401 (1992)

${ }^{50}$ C. Schwab, in Eighth International Workshop on Stellarators, (Kharkov, 1991) p. 491

${ }^{51}$ A. Iiyoshi, M. Fujiwara, O. Motojima, N. Ohyabu, and K. Yamazaki, Fusion Technology 17, 169 (1990)

${ }^{52} \mathrm{~K}$. Ichiguchi, Y. Nakamura, and M. Wakatani, private communication; H. J. Gardner and K. Ichiguchi, National linstitute for Fusion Science Report NIFS-231 (1993)

${ }^{53}$ Y. Nakamura, M. Wakatani, and J. L. Johnson, Kyoto University Plasma Physics Laboratory Report PPLK-R-58 (1992)

${ }^{54}$ R. C. Grimm, J. M. Greene, and J. L. Johnson, in Methods of Computational Physics, (J. Killeen, Ed., Academic Press, New York, 1976), vol. 16, p. 253

${ }^{55}$ G. Rewoldt, M. Wakatani, and J. L. Johnson, Plasma Physics and Controlled Fusion 29, 1643 (1987)

${ }^{58}$ L. M. Degtyarev, V. V. Drozdov, M. I. Mikhailov, V. D. Pustovitov, and V. D. Shafranov, Sov. J. Plasma Physics, 11. 22 (1985)

${ }^{57}$ L. M. Degtyarev, V. V. Drozdov, and Yu. Yu. Poshekhonov, in Proceedings of the 14th European Conference on Controlled Fusion and Plasma Plyysics (Madrid, 1987) Vol. 11D, Part 1, P. 377.

${ }^{58}$ L. M. Degtyarev and S. Yu. Medvedev, Comput. Phys. Commun. 43, 29 (1986)

${ }^{59}$ L. M. Degtyarev and V. V. Drozdov, Comput. Phys. Reports 2, 341 (1985)

${ }^{60}$ R. Gruber, F. Troyon, D. Berger, L. C. Bernard, S. Rousset, R. Schreiber. W. Kerner, W. Schneider. and K. V. Roberts, Comput. Phys. Commun. 21, 323 (1981)

${ }^{61}$ R. C. Grimm, R. L. Dewar, and J. Manickam, J. Comput. Phys. 49, 94 (1983)

${ }^{62}$ A. Bondeson and G. Y. Fu, Comput. Phys. Commun. 66, 167 (1991)

${ }^{63}$ H. Sugama and M. Wakatani, J. Phys. Soc. Japan 58, 1128 (1989) 
Tables

TABLE I. Shape of the plasma boundary for an LHD equilibrium with a $15 \mathrm{~cm}$ inward shift

\begin{tabular}{rrrr}
$\mathrm{m}$ & $\mathrm{n}$ & $\mathrm{R}$ & \multicolumn{1}{c}{$\mathrm{Z}$} \\
$\mathbf{0}$ & -3 & $-7.9800 \mathrm{E}-04$ & $8.4445 \mathrm{E}-04$ \\
0 & -2 & $4.1327 \mathrm{E}-03$ & $-3.0926 \mathrm{E}-04$ \\
0 & -1 & $5.1337 \mathrm{E}-04$ & $-1.0588 \mathrm{E}-02$ \\
0 & 0 & $3.7447 \mathrm{E}-00$ & $0.0000 \mathrm{E}-00$ \\
1 & -3 & $2.0726 \mathrm{E}-05$ & $5.0860 \mathrm{E}-06$ \\
1 & -2 & $6.2691 \mathrm{E}-04$ & $-6.4388 \mathrm{E}-04$ \\
1 & -1 & $-3.3552 \mathrm{E}-03$ & $-3.3914 \mathrm{E}-03$ \\
1 & 0 & $6.0354 \mathrm{E}-01$ & $-6.0471 \mathrm{E}-01$ \\
1 & 1 & $-1.8553 \mathrm{E}-01$ & $-1.8557 \mathrm{E}-01$ \\
1 & 2 & $3.7961 \mathrm{E}-04$ & $-8.9118 \mathrm{E}-04$ \\
1 & 3 & $-3.5841 \mathrm{E}-04$ & $-3.7405 \mathrm{E}-04$ \\
2 & -3 & $-4.7804 \mathrm{E}-05$ & $3.7281 \mathrm{E}-05$ \\
2 & -2 & $-1.2175 \mathrm{E}-03$ & $1.3435 \mathrm{E}-03$ \\
2 & -1 & $2.4161 \mathrm{E}-03$ & $-3.7336 \mathrm{E}-03$ \\
2 & 0 & $-2.9558 \mathrm{E}-03$ & $6.8692 \mathrm{E}-03$ \\
2 & 1 & $-4.9662 \mathrm{E}-03$ & $-1.2225 \mathrm{E}-02$ \\
2 & 2 & $3.2055 \mathrm{E}-03$ & $4.4494 \mathrm{E}-03$ \\
2 & 3 & $3.1796 \mathrm{E}-04$ & $-9.1183 \mathrm{E}-05$ \\
3 & -3 & $-6.6504 \mathrm{E}-00$ & $2.6090 \mathrm{E}-05$ \\
3 & -2 & $-3.0066 \mathrm{E}-05$ & $-7.4684 \mathrm{E}-05$ \\
3 & -1 & $1.0442 \mathrm{E}-03$ & $-8.3010 \mathrm{E}-04$ \\
3 & 0 & $2.5582 \mathrm{E}-03$ & $3.1130 \mathrm{E}-03$ \\
3 & 1 & $9.8731 \mathrm{E}-05$ & $-1.6454 \mathrm{E}-03$ \\
3 & 2 & $2.6068 \mathrm{E}-03$ & $2.6006 \mathrm{E}-03$ \\
3 & 3 & $9.0982 \mathrm{E}-05$ & $7.3865 \mathrm{E}-05$
\end{tabular}


TABLE II. Instability eigenvalues for the fastest growing "fixed boundary" mode with toroidal mode number $n=2$ in an LHD configuration with the outer boundary given by the parameters of Table $I$ and the pressure distribution of Eq. (2), $p=p_{0}\left(1-\psi^{2}\right)^{2}$, with $\psi$ the poloidal flux.

$\begin{array}{lccrc}\beta_{0} & \text { KSTEP } & \text { TWIST } & \text { RESORM } & \text { CHAFAR } \\ \mathbf{3 . 0 0 \%} & -8.55 \times 10^{-4} & & -8.168 \times 10^{-4} & -3.814 \times 10^{-5} \\ 3.24 \% & & -8.8 \times 10^{-4} & & \\ 4.00 \% & -4.80 \times 10^{-3} & & -4.83 \times 10^{-3} & -2.813 \times 10^{-4} \\ \mathbf{4 . 3 2 \%} & & -4.57 \times 10^{-3} & & \\ \mathbf{5 . 0 0 \%} & -9.76 \times 10^{-3} & & -1.016 \times 10^{-2} & -6.968 \times 10^{-4} \\ \mathbf{5 . 4 4 \%} & & -9.33 \times 10^{-3} & & \\ \mathbf{6 . 0 0 \%} & -1.344 \times 10^{-2} & & -1.418 \times 10^{-2} & -1.157 \times 10^{-3} \\ 6.60 \% & & -1.30 \times 10^{-2} & & \\ 7.00 \% & -1.479 \times 10^{-2} & & -1.549 \times 10^{-2} & -1.506 \times 10^{-3} \\ \mathbf{7 . 8 1 \%} & & -1.38 \times 10^{-2} & & \\ 8.00 \% & -1.350 \times 10^{-2} & & -1.357 \times 10^{-2} & -1.460 \times 10^{-3} \\ 8.75 \% & & -1.24 \times 10^{-2} & & \\ 9.00 \% & -1.067 \times 10^{-2} & & -1.036 \times 10^{-2} & -1.022 \times 10^{-3} \\ 10.0 \% & -7.84 \times 10^{-3} & & -0.780 \times 10^{-2} & -6.469 \times 10^{-4} \\ 11.0 \% & -6.03 \times 10^{-3} & & & -4.899 \times 10^{-4} \\ 12.0 \% & -5.61 \times 10^{-3} & & & -5.621 \times 10^{-4} \\ 13.0 \% & -6.04 \times 10^{-3} & & & -7.560 \times 10^{-4} \\ 14.0 \% & -7.89 \times 10^{-3} & & & -1.146 \times 10^{-3} \\ 15.0 \% & -1.544 \times 10^{-2} & & & -1.763 \times 10^{-3}\end{array}$


TABLE III. Instability eigenvalues for the fastest growing "fixed boundary" mode with toroidal mode number $n=2$ in an LHD configuration with the outer boundary given by the parameters of Table $I$ and the pressure distribution of Eq. (3), $p=p_{0}\left(1-\hat{\psi}^{2}\right)^{2}$, with $\hat{\psi}$ the toroidal flux.

\begin{tabular}{|c|c|c|c|c|}
\hline & \multicolumn{2}{|c|}{ FIXED BOUNDARY } & \multicolumn{2}{|c|}{ FREE BOUNDARY } \\
\hline$\beta_{0}$ & KSTEP & TERPSICHORE & KSTEP & TERPSICHORE \\
\hline $2 \%$ & $-9.04 \times 10^{-5}$ & & $-1.11 \times 10^{-4}$ & \\
\hline $2.07 \%$ & & $-3.00 \times 10^{-6}$ & & $-9.00 \times 10^{-6}$ \\
\hline $2.44 \%$ & & $-8.80 \times 10^{-5}$ & & $-1.44 \times 10^{-4}$ \\
\hline $2.97 \%$ & & $-4.30 \times 10^{-4}$ & & $-7.26 \times 10^{-4}$ \\
\hline $3 \%$ & $-7.47 \times 10^{-4}$ & & $-9.20 \times 10^{-4}$ & \\
\hline $3.86 \%$ & & $-1.39 \times 10^{-3}$ & & $-2.57 \times 10^{-3}$ \\
\hline $4 \%$ & $-2.36 \times 10^{-3}$ & & $-3.00 \times 10^{-3}$ & \\
\hline $4.72 \%$ & & $-2.19 \times 10^{-3}$ & & $-4.70 \times 10^{-3}$ \\
\hline $\mathbf{5 \%}$ & $-3.37 \times 10^{-3}$ & & $-4.41 \times 10^{-3}$ & \\
\hline $5.55 \%$ & & $-2.44 \times 10^{-3}$ & & $-7.00 \times 10^{-3}$ \\
\hline $6 \%$ & $-3.16 \times 10^{-3}$ & & $-4.18 \times 10^{-3}$ & \\
\hline $6.36 \%$ & & $-2.01 \times 10^{-3}$ & & $-9.97 \times 10^{-3}$ \\
\hline $\begin{array}{r}7 \% \\
7.14 \%\end{array}$ & $-2.59 \times 10^{-3}$ & $-1.60 \times 10^{-3}$ & $-7.06 \times 10^{-3}$ & $-1.29 \times 10^{-2}$ \\
\hline $7.89 \%$ & & $-2.25 \times 10^{-3}$ & & $-1.50 \times 10^{-2}$ \\
\hline $8 \%$ & $-3.11 \times 10^{-3}$ & & $-1.87 \times 10^{-2}$ & \\
\hline $8.62 \%$ & & $-9.80 \times 10^{-4}$ & & $-1.59 \times 10^{-2}$ \\
\hline $9 \%$ & $\begin{array}{l}-1.41 \times 10^{-3} \\
-3.43 \times 10^{-3}\end{array}$ & & $-4.13 \times 10^{-2}$ & \\
\hline & & & & \\
\hline
\end{tabular}


TABLE IV. Instability eigenvalues for the fastest growing "fixed boundary" mode with toroidal mode number $n=3$ in an LHD configuration with the outer boundary given by the parameters of Table $I$ and the pressure distribution of Eq. (2), $p=p_{0}\left(1-\psi^{2}\right)^{2}$, with $\psi$ the poloidal flux.

$\begin{array}{lcc}\beta_{0} & \text { KSTEP } & \text { TWIST } \\ \mathbf{2 . 0 0 \%} & -1.54 \times 10^{-6} & \\ 3.00 \% & -2.01 \times 10^{-3} & \\ 3.24 \% & & -1.99 \times 10^{-3} \\ 4.00 \% & -9.11 \times 10^{-3} & \\ 4.32 \% & & -7.81 \times 10^{-3} \\ 5.00 \% & -1.68 \times 10^{-2} & \\ 5.44 \% & & -1.37 \times 10^{-2} \\ 6.00 \% & -2.14 \times 10^{-2} & \\ 6.60 \% & -2.20 \times 10^{-2} & -1.66 \times 10^{-2} \\ 7.00 \% & -2.15 \times 10^{-2} & \\ 7.81 \% & & -1.56 \times 10^{-2} \\ 8.00 \% & -1.84 \times 10^{-2} & \\ 8.75 \% & & -1.87 \times 10^{-2} \\ 9.00 \% & -1.49 \times 10^{-2} & \\ 10.00 \% & -1.16 \times 10^{-2} & \end{array}$


TABLE V. Instability eigenvalues for the fastest growing "fixed boundary" mode with toroidal mode number $n=3$ in an LHD configuration with the outer boundary given by the parameters of Table $I$ and the pressure distribution of Eq. $(4), p=\frac{p_{0}}{8} \frac{V^{\prime}}{V^{\prime}(0)}\left[5\left(1-\hat{\psi}^{2}\right)^{2}+3(1-\hat{\psi})\right]$, with $\hat{\psi}$ the toroidal flux and $V(\hat{\psi})$ the volume.

$\begin{array}{lccc}\beta_{0} & \text { KSTEP } & \text { RESORM } & \text { CAS3D } \\ 1.96 \% & -2.01 \times 10^{-5} & & \\ 1.97 \% & & -4.51 \times 10^{-5} & -2.17 \times 10^{-5} \\ 2.12 \% & -7.29 \times 10^{-5} & & \\ 2.21 \% & & & -7.55 \times 10^{-5} \\ 2.30 \% & -1.80 \times 10^{-4} & & \\ 2.43 \% & & -3.43 \times 10^{-4} & -2.55 \times 10^{-4} \\ 2.48 \% & -3.53 \times 10^{-4} & & \\ 2.65 \% & -5.97 \times 10^{-4} & & \\ 2.82 \% & -9.11 \times 10^{-4} & & -8.62 \times 10^{-4} \\ 2.88 \% & & -1.08 \times 10^{-3} & -1.74 \times 10^{-3} \\ 3.31 \% & & & \\ 3.66 \% & -3.26 \times 10^{-3} & & -2.88 \times 10^{-3} \\ 3.74 \% & & -3.59 \times 10^{-3} & -2010\end{array}$




\section{Figures}

FIG. 1. $p(\psi)$ as a function of the normalized poloidal flux for the different pressure distributions with $\beta_{0}=4 \% ; p_{I}$ corresponds to Eq. (2), $p_{11}$ to Eq. (3), and $p_{I I I}$ to Eq.(4).

FIG. 2. The rotational transform $t(\psi)$ as a function of the normalized poloidal flux for the different pressure distributions with $\beta_{0}=4 \%$.

FIG. 3. The eigenvalues $\Lambda$ as functions of $\beta_{0}$ for an $n=2$ "fixed boundary" node in the LHD equilibrium with $p$ given by Eq. (2) as calculated by the KSTEP code, the TWIST code, the RESORM code, and the CHAFAR code. The eigenvalues from the CHAFAR have been mutiplied by a factor of 10 .

FIG. 4. Fourier components of the minimizing displacement vector normal to the magnetic surfaces, $\xi \cdot \nabla \psi$, as functions of the normalized poloidal flux $\psi$ for the $n=2$ "fixed boundary" mode in the LHD equilibrium where $p$ is given by Eq. (2) with $\beta_{0} \approx 4 \%$. (a) KSTEP, (b) TWIST, (c) RESORM, and (d) CHAFAR.

FIG. 5. The eigenvalues $\Lambda$ as functions of $\beta_{0}$ for an $n=2$-fixed boundary ${ }^{-}$Inode in the LHD equilibrium with $p$ given by Eq. (3) as calculated by the KSTEP and TERPSICHORE codes.

FIG. 6. Fourier components of the minimizing displacement vector normal to the magnetic surfaces $\xi \cdot \nabla \psi$ as functions of the normalized poloidal flux $\psi$ for the $n=2$ "fixed boundary" mode in the LHD equilibrium where $p$ is given by Eq. (3) with $\beta_{0} \approx 4 \%$. (a) KSTEP, (b) TERPSICHORE.

FIG. 7. The eigenvalues $\Lambda$ as functions of $\beta_{0}$ for an $n=2$ free boundary" mode in the LHD equilibrium with $p$ given by Eq. (3) as calculated by the KSTEP and TERPSICHORE codes.

FIG. 8. Fourier components of the mininizing displacement vector normal to the magnetic surfaces $\xi \cdot \nabla \psi$ as a function of the normalized poloidal flux $\psi$ for the $n=2$ "free boundary" mode in the LHD equilibrium where $p$ is given by Eq. (3) with $\beta_{0} \approx 7 \%$. (a) KSTEP, (b) TERPSICHORE.

FIC. 9. The eigenvalues $\Lambda$ as functions of $\beta_{0}$ for an $n=3$ "fixed boundary" mode in the LHD equilibrium with $p$ given by Eq. (2) as calculated by the KSTEP and the TWIST codes.

FIG. 10. Fourier components of the minimizing displacement vector normal to the magnetic surfaces $\xi \cdot \nabla \psi$ as functions of the normalized poloidal flux $\psi$ for the $n=3$ "fixed boundary" mode in the LHD equilibrium where $p$ is given by Eq. (2) with $\beta_{0}=6.6 \%$. (a) KSTEP, (b) TWIST.

FIG. 11. The eigenvalues $\Lambda$ as functions of $\beta_{0}$ for an $n=3$ "fixed boundary" mode in the LHD equilibrium with $p$ is given by Eq. (4) as calculated by the KSTEP code the RESORM code, and the CAS3D code.

FIG. 12. Fourier components of the minimizing displacement vector normal to the magnetic surfaces $\xi \cdot \nabla \psi$ as functions of the normalized poloidal flux $\psi$ for the $n=3$ "fixed boundary" mode in an LHD equilibrium where $p$ is given by Eq. (4) with $\beta_{0} \approx 4 \%$. (a) KSTEP, (b) RESORM, (c) CAS3D. 


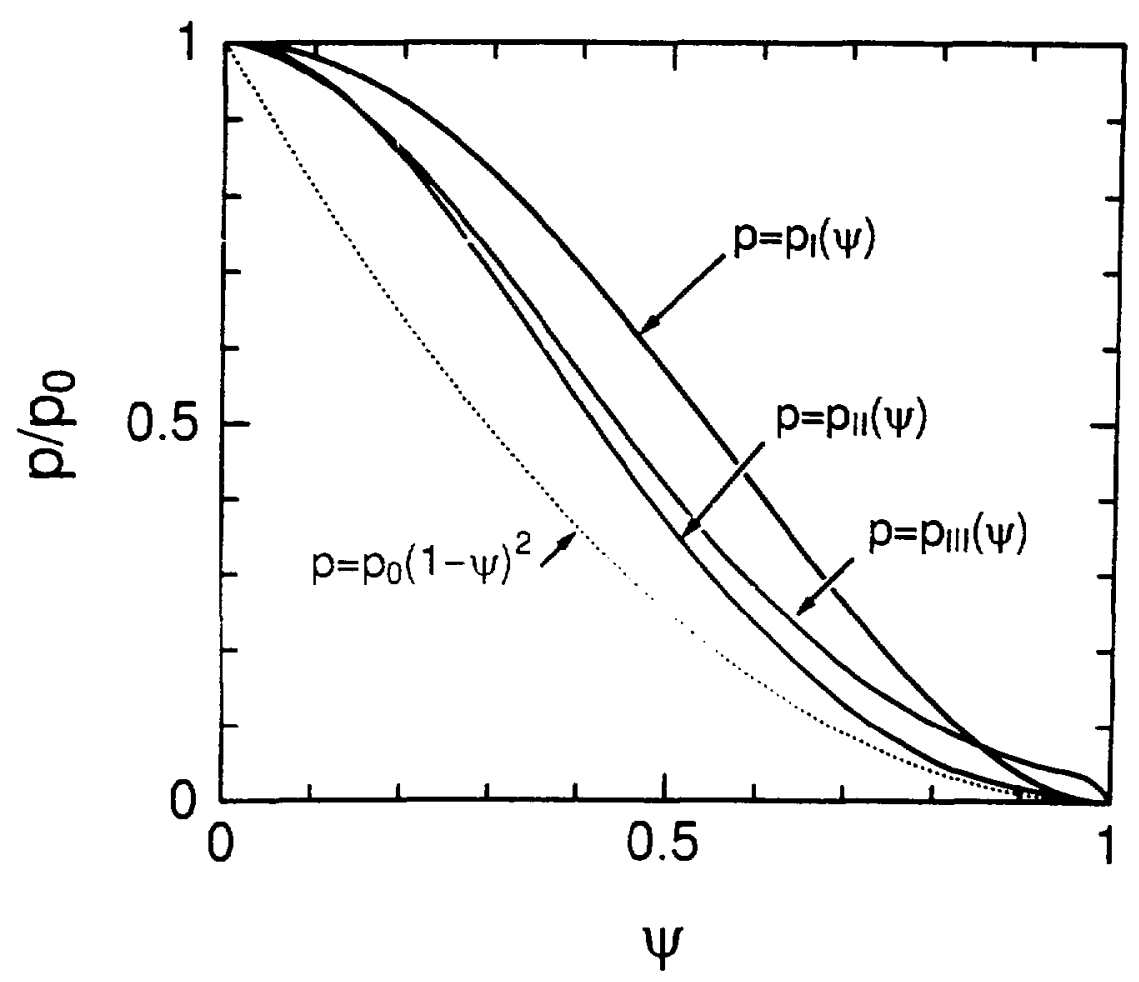

FIG. 1. $p(\psi)$ as a function of the normalized poloidal flux for the different preasure distributions with $\beta_{0}=4 \% ; p_{1}$ corresponds to Eq. (2). $p_{\text {TI }}$ to Eq. (3), and pil to Eq.(4). 


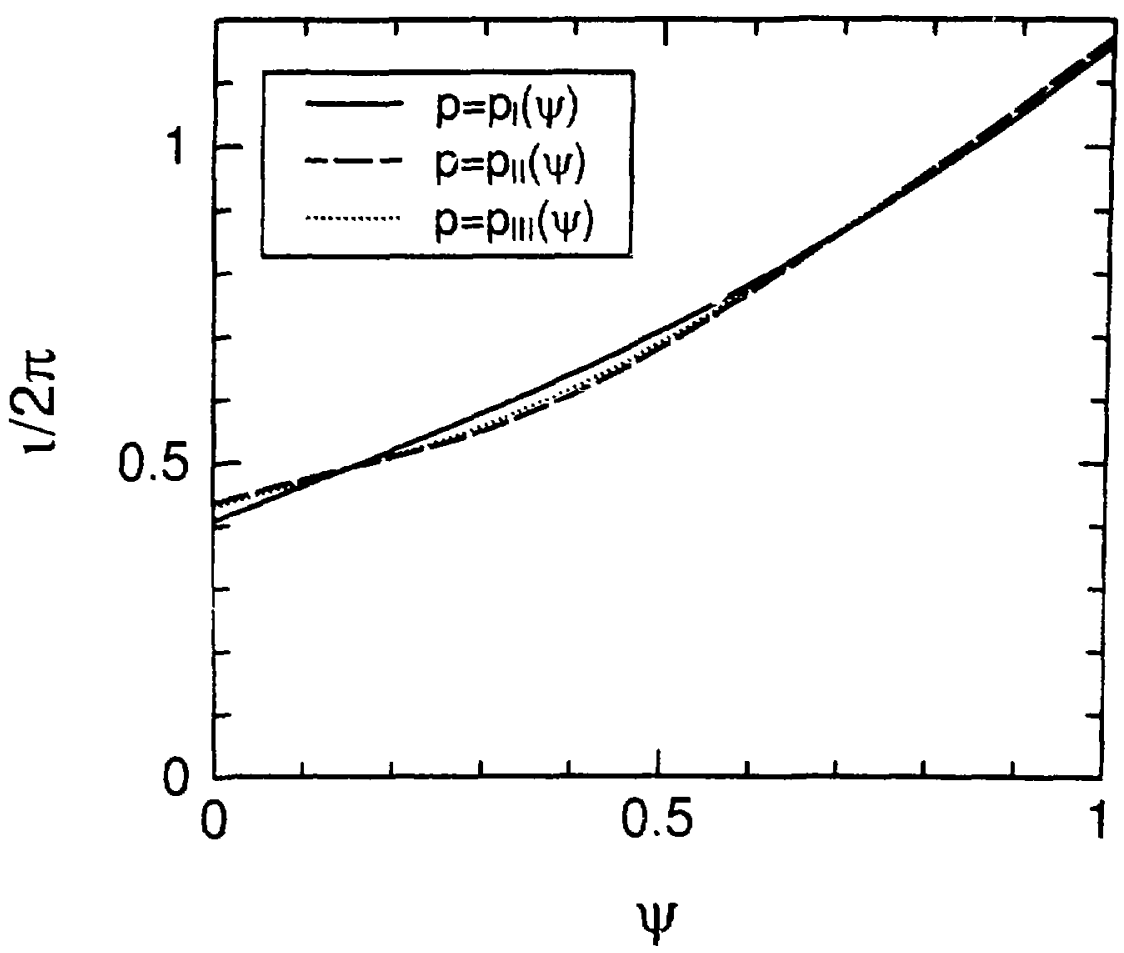

FIG. 2. The rotational transform $4(\forall)$ as a function of the normalized poloidal flux for the different pressure distributions with $\beta_{0}=4 \%$. 


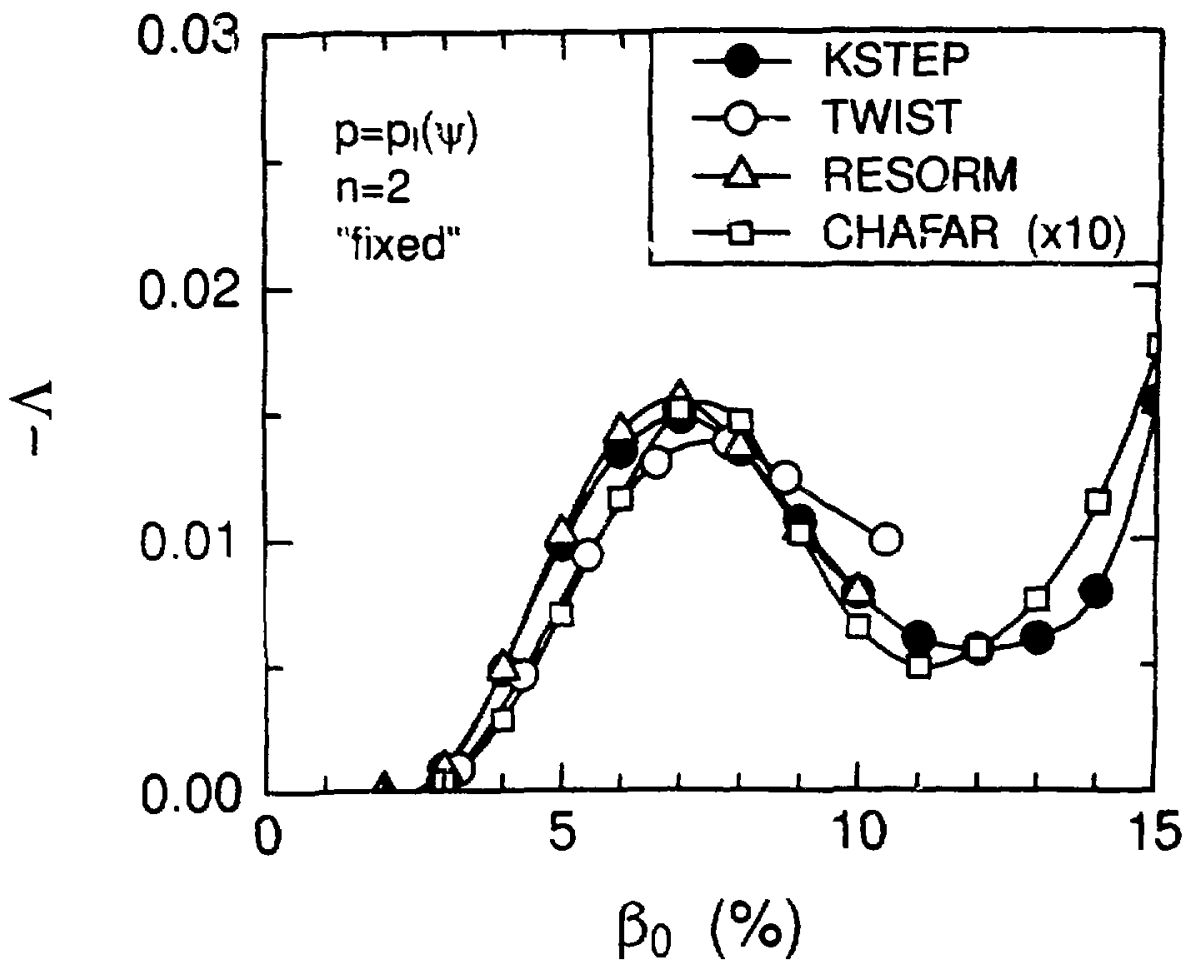

FIG. 3. The eigenvalues $\Lambda$ as functions of $\beta_{6}$ for an $n=2$ "fixed boundary" mode in the LHD equilibrium with $p$ given by Eq. (2) as calculated by the KSTEP code, the TWTST code, the RESORM code, and the CHAFAR code. The eigenvalues from the CHAFAR have been mutiplied by a factor of 10 . 

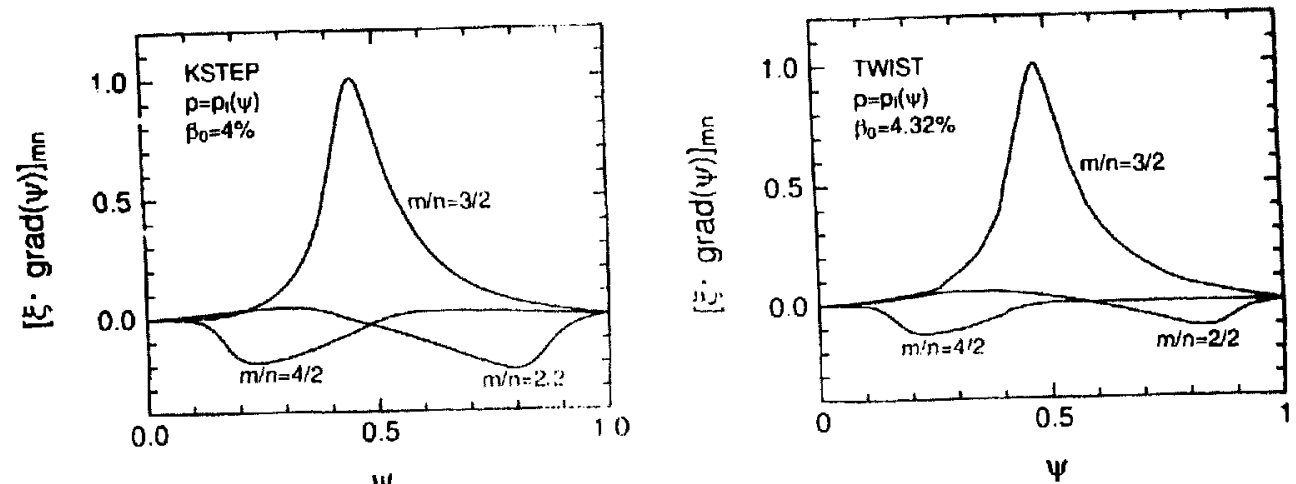

ư

$\Psi$
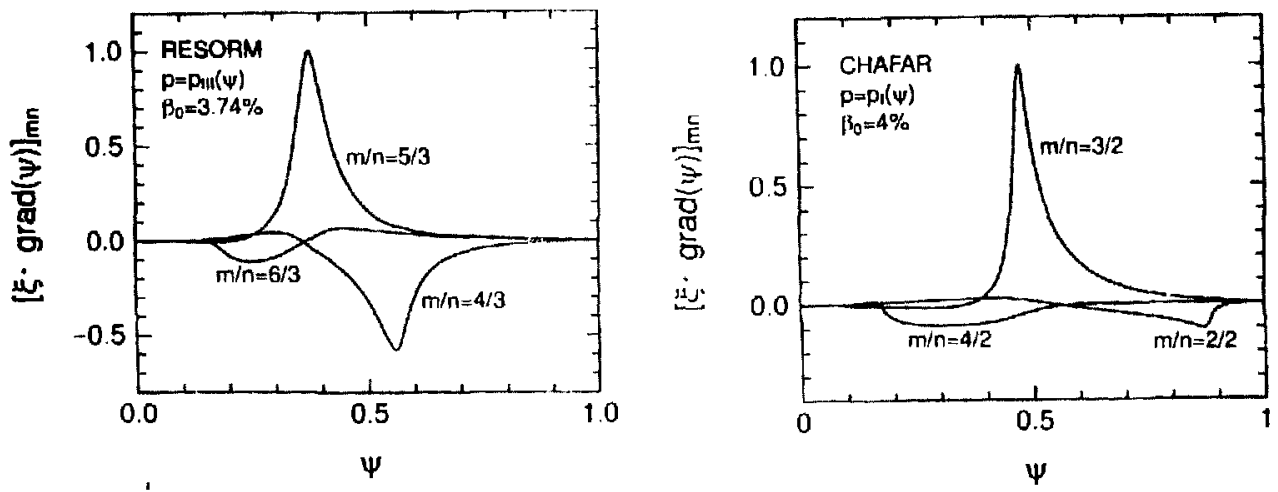

FIG. 4. Fourier components of the minimixing thisplawenent vector normal to the magntic ourfaco,

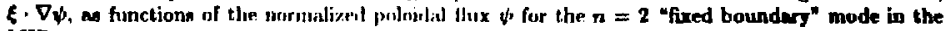
LHD equilibrium where $p$ is given by lis. (2) with $/ h_{n} \approx 4 \%$. (a) KSTEP, (b) TWIST, (c) RESORM, and (d) CHAFAR. 


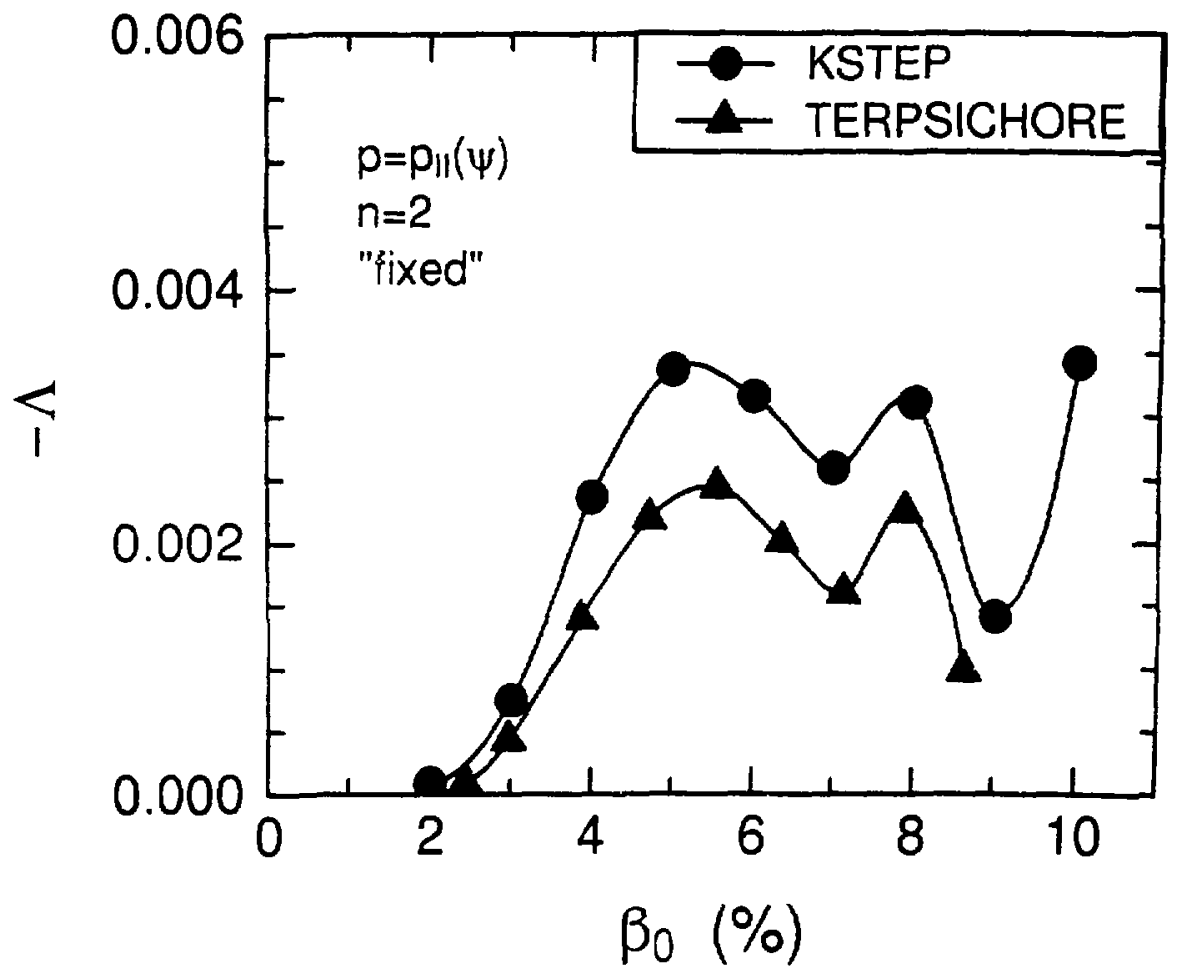

FIG. 5. The eigenvalue $\Lambda$ as functions of $\beta_{0}$ for an $n=2$ "fixed boundary" mode in the LHD equilibrium with p given by Eq. (3) as calculated by the KSTEP and TERPSICHORE codes. 

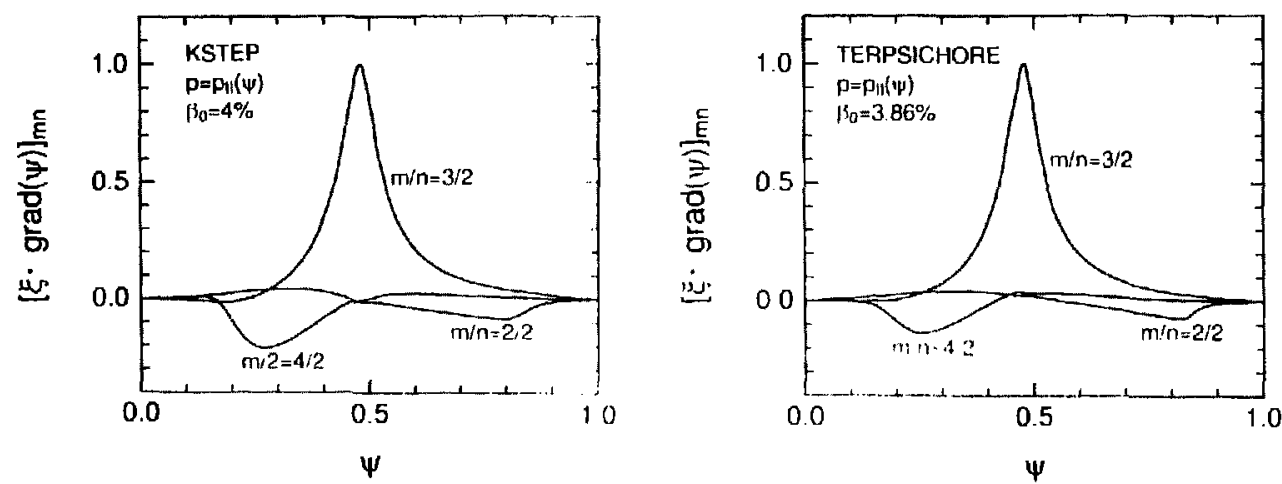

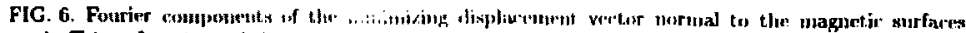

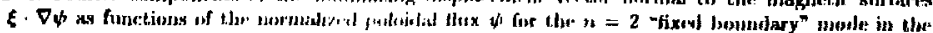

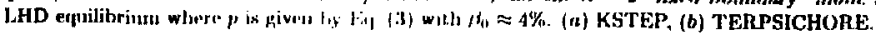




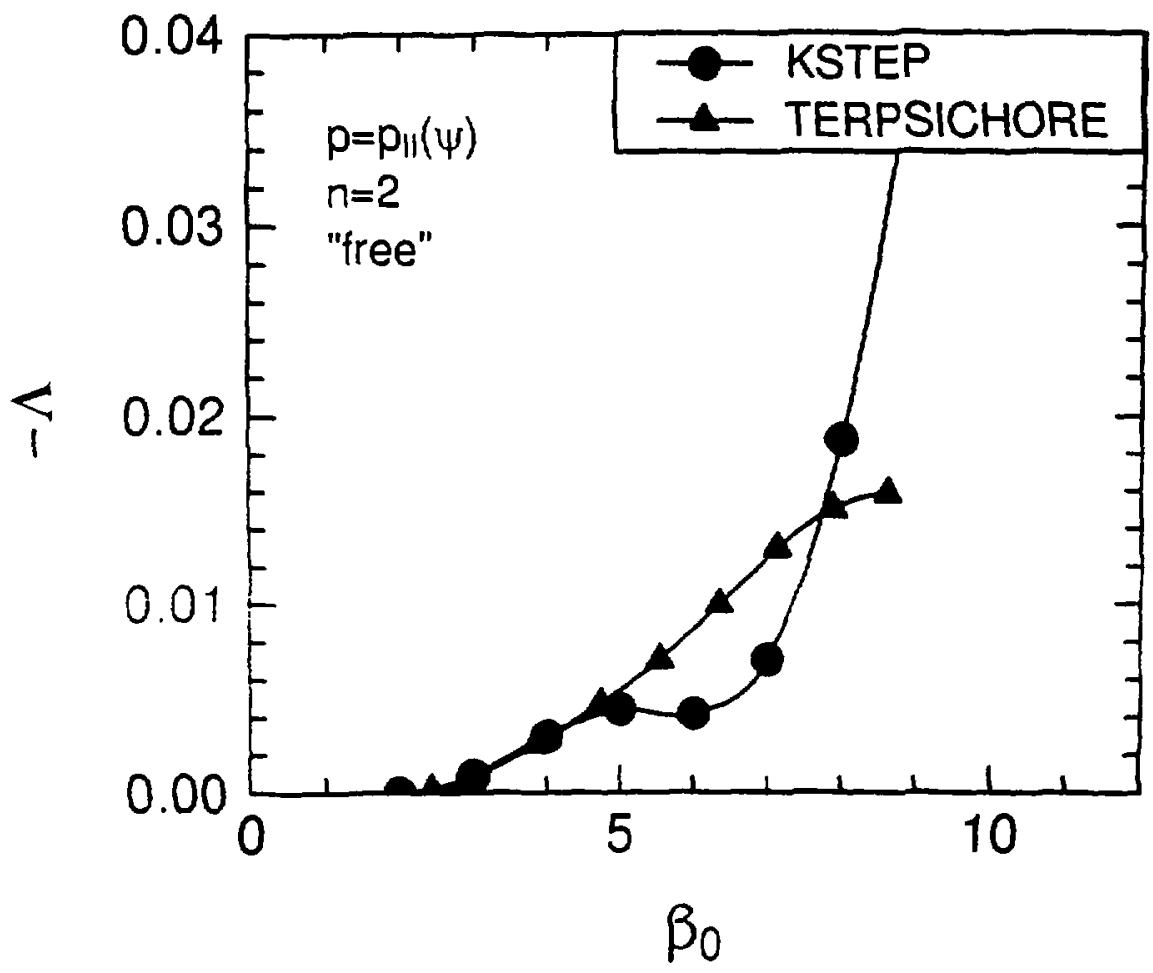

FIG. 7 . The eigenvalues $\Lambda$ as functions of $\beta_{0}$ for an $n=2$ free boundary ${ }^{n}$ mode in the LHD equilibrium with $p$ givet by Ex. (3) as calculated by the KS.EP and TERPSICHORE codes. 

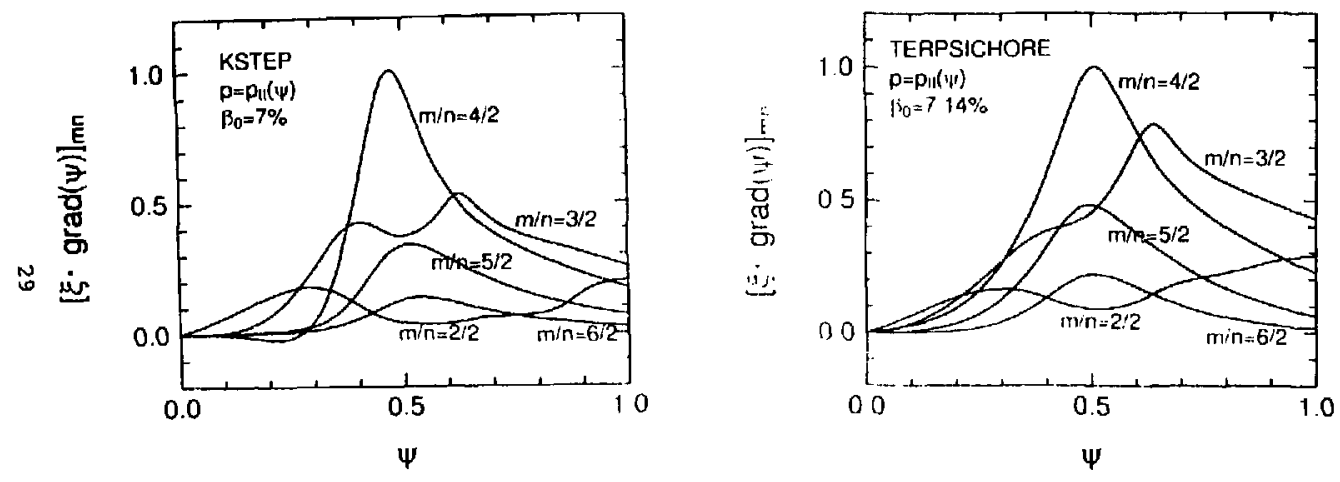

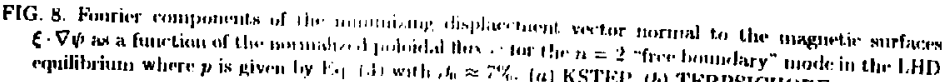




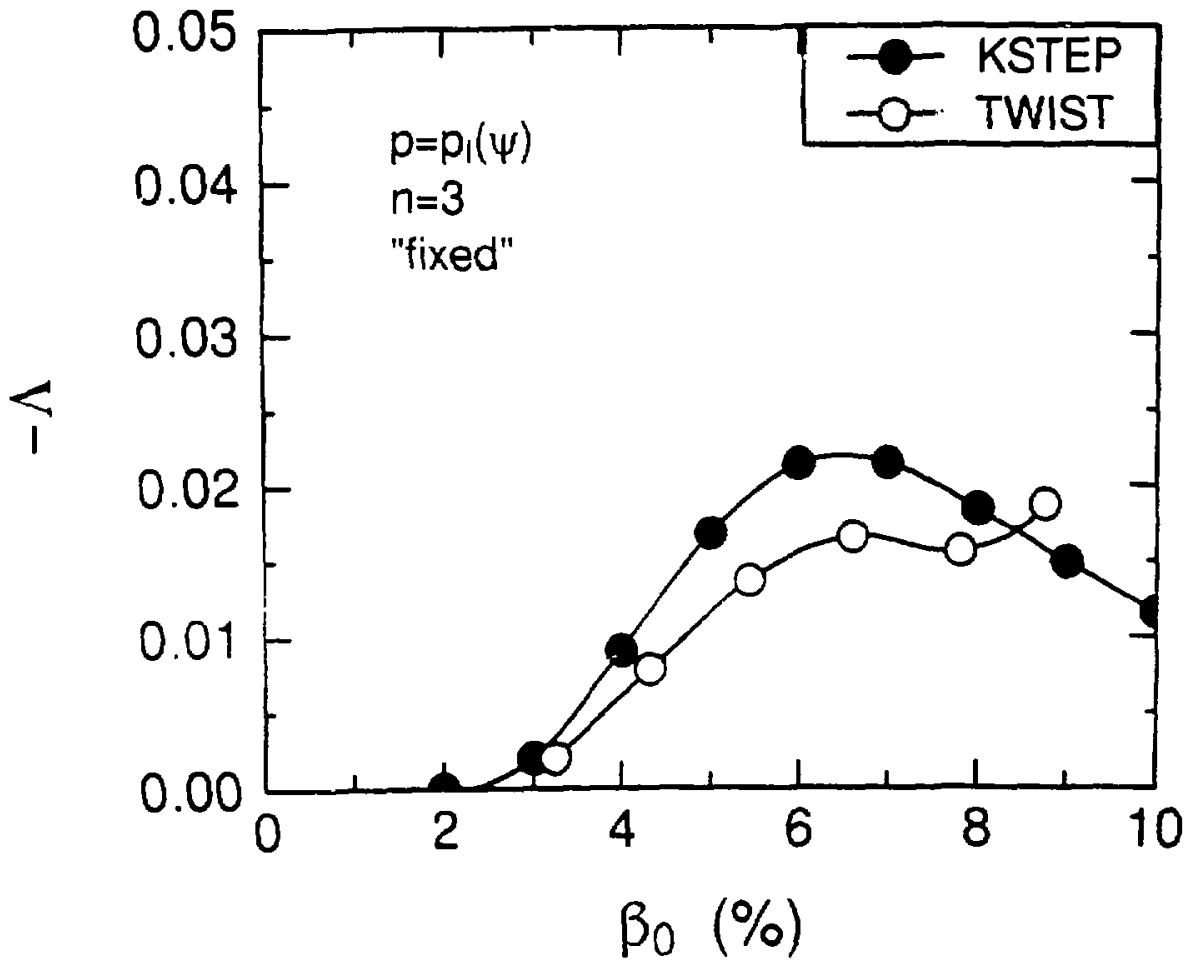

FIG. 9. The eigenvalues $A$ as functions of $\beta_{0}$ for an $n=3$-fixed boundary" mode in the LHD equilibrium with $p$ given by $E_{1.1}(2)$ as calculated by the KSTEP and the TWIST codes. 

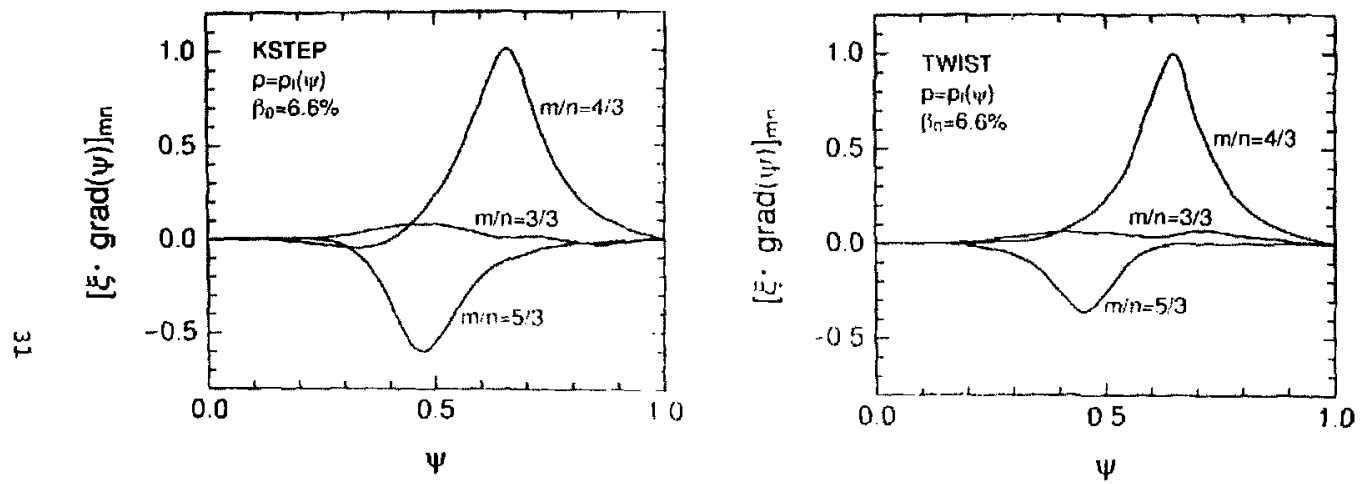

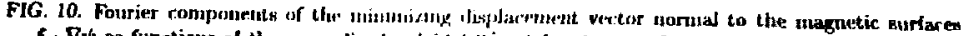

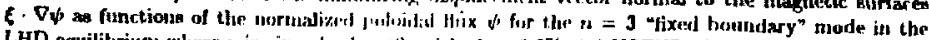

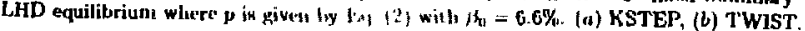




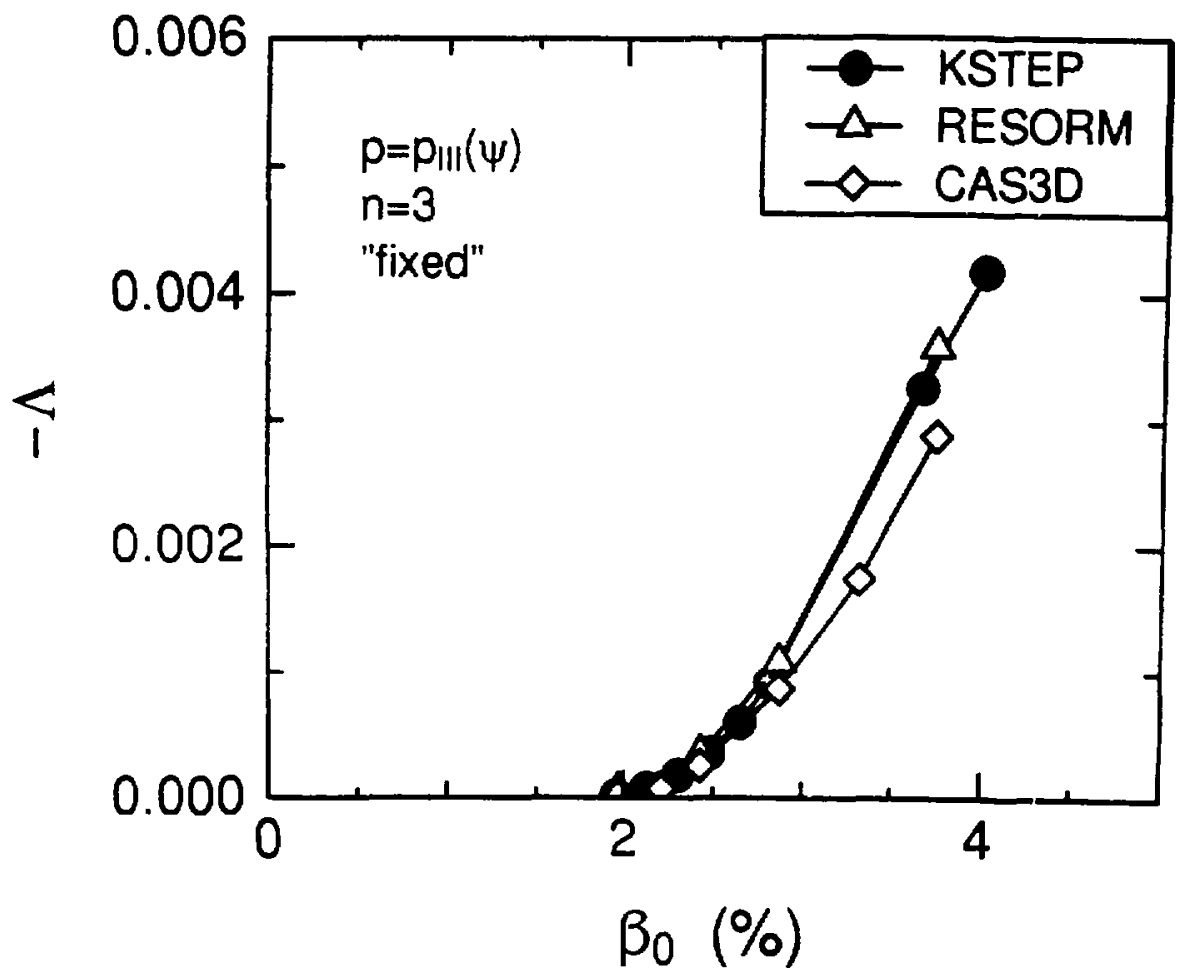

FIG. 11. The eigenvalues $\Lambda$ as functions of $\beta_{6}$ for an $n=3$ "fixed boundary" mode in the LFD equilibrivm with $p$ is given by Eq. (4) as calculated by the KSTEP code the RESORM code, and the CAS3D code. 

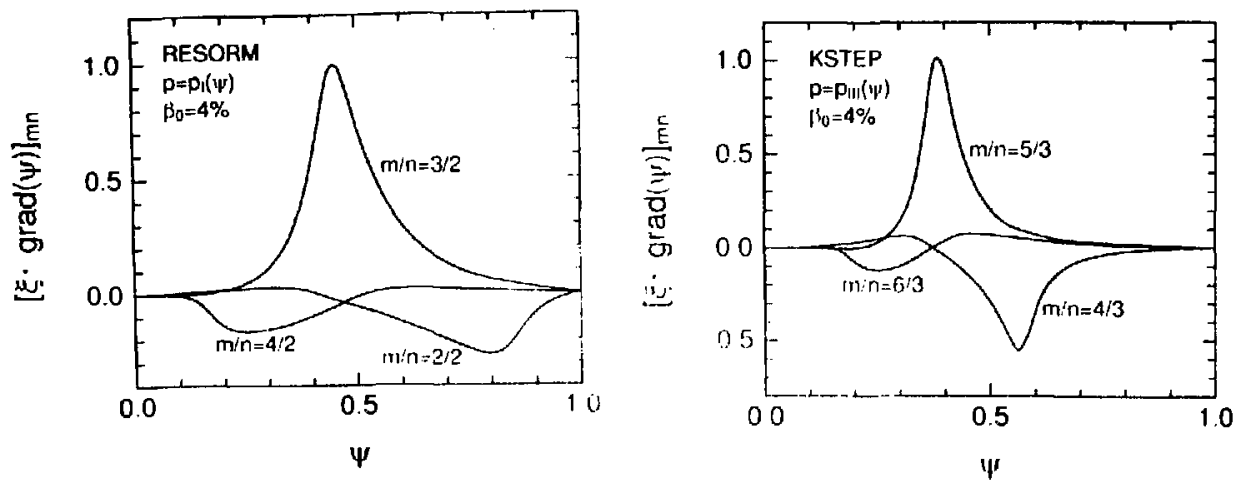

$\boldsymbol{\omega}$

$\Psi$

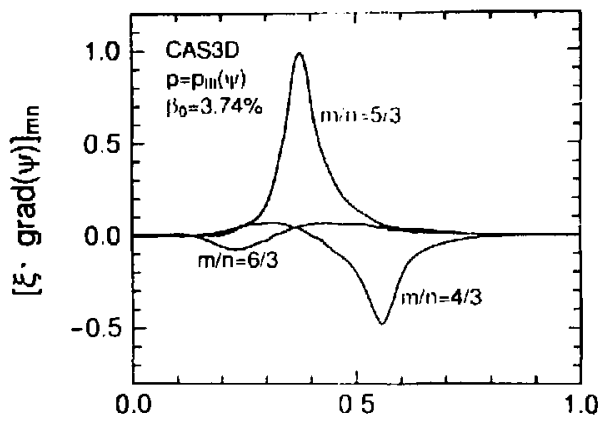

if

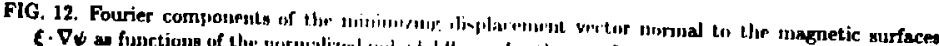

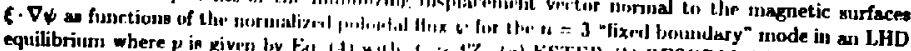

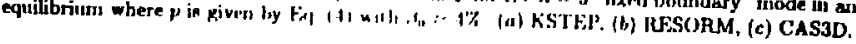


Dr. F. Peoloni, Univ. of Wollongong. AUSTRALIA

Prof. R.C. Cross, Univ. of Sydney, AUSTRuLlA

Plasma Pasearch Lob., Australien Nat. Univ., AUSTRALIA

Prol. I.R. Jones, Flinders Univ, AUSTFALIA

Prof. F. Cap, Inst for Theoretical Physics, AUSTRIA

Prof. M. Heindier, Instibut für Thoorebieche Physik, AUSTRIA

Prof. M Goossens, Astronomisch Instituut, BELGIUM

Ecole Royale Mituin, Lab. de Phy. Plasmas, BELGIUM

Commicsion-European, DG. XII.Fusion Prog., BELGIUM

Prol. R. Boucique, Rijksuniversibit Cent, BELGIUM

Dr. P.H. Sakanaka, Instituto Fisica, BRAZIL

Prol. Dr. I.C. Nascimento, Instituto Fisica, Sao Paulo, BRAZIL Instituto Neciond De Pesquisas Especiais-INPE, BPAZIL

Documents Office, Atomic Energy of Canada Lid., CANADA

Ms. M. Morin, CCFWTokamak de Varennes, CANADA

Dr. M.P. Bachynski, MPB Techrologies, Inc., CANADA

Dr. H.M. Skarsgard, Univ. of Saskatchowan, CANADA

Prof. J. Teichmann, Univ. of Montreal, CANADA

Prof. S.R. Sreenivasan, Univ. of Calgary. CANADA

Prot. R. Marchand, INRS-Energie et Materiaux, CANADA

Dr. R. Bolton, Centre canadien de fusion magnétique, CANADA

Dr. C.R. James, Univ. of Alberta, CANADA

Dr. P. Lukác, Komenského Universzita, CZECHOSLOVAKIA

The Libranan, Culham Laboratory. ENGLAND

Libray, R61, Ruthertord Appleton Laboratory, ENGLAND

Mrs. S.A. Hutchinson, JET Libray, ENGLAND

Dr. S.C. Sharma, Univ. of South Paxific, FIJI ISLANDS

P. Măhonen, Univ. of Helsinki, FINUAND

Pro!. MN. Bussac. Ecole Polylechnique.. FRANCE

C. Mouttet, Lab. de Physique des Milieux lonisós, FRANCE

J. Rade CEN/CADARACHE - Bat 506, FRANCE

Pral. E. Economou, Univ. of Crete, GREECE

Ms. C. Rinni, Univ. of loannina, GREECE

Preprini Library, Hungarian Academy of Sci., HUNGARY

Or. B. DasGupta, Saha Inst of Nuclear Physics. INDIA

Dr. P. Kaw, Inst. lor Plasma Research, INDIA

Dr. P. Rosenau, Israel Inst. of Technology, ISRAEL

Librarian, Inemational Center for Theo Physics, ITALY

Miss C. De Palo, Associazione EURATOM-ENEA , ITALY

Dr. G. Grosso, Istituto di Fisica del Plasma, ITALY

Prof. G. Rostangni, Istituto Gas lonizzati Del Cnr, ITALY
Dr. H. Yamato. Toshiba Res \& Devel Center, JAPAN

Prof. I. Kawakami, Hiroshima Univ., JAPAN

Prof. K. Nishikawa, Hiroshima Univ., JAPAN

Librarien, Naka Fusion Research Establishment, JAERI, JAPAN

Director, Japen Atomic Energy Research inst., JAPAN

Prof. S. Ioh, Kyushu Univ., JAPAN

Research inlo. Ctr., National Instit. lor Fusion Scienć, JAPAN

Prof. S. Tanaka, Kyoto Univ., JAPAN

Library, Kyoto Univ., JAPAN

Prof. N. Inous, Univ. of Tokyo, JAPAN

Secretary, Plasma Section, Electrotechnical Lab., JAPAN

Dr. O. Mitarai, Kumamoto Inst. of Technology, JAPAN

Dr. G.S. Lee, Korea Basic Sci. Ctr., KOREA

J. Hyeon Sook, Korea Atomic Energy Research Inst, KOREA

D.I. Choi, The Korea Adv. Inst. of Sci. \& Tech., KOREA

Leandro Melendez Lugo, inst. Nac1. de Inves. Nucl, MEXICO

Prof. B.S. Liley, Univ. of Waikato, NEW ZEALAND

Inst of Physics, Chinese Acad Sci PEOPLE'S REP. OF CHINA

Libray. Inst. of Plasma Physics, PEOPLE'S REP. OF CHINA

Tsinghua Univ. Library, PEOPLE'S REPUBLIC OF CHINA

2. Li, S.W. InsI Physias, PEOPLE'S REPUBLIC OF CHINA

Prof. J.A.C. Cabral, Instituto Superior Tecrico, PORTUGAL

Prot. M.A. Hellberg, Univ. of Natal, S. AFRICA

Prof. D.E. Kim, Pohang Inst. of Sci. \& Tech., SO. KOREA

Prof. C.I.E.M.A.T, Fusion Division Library, SPAiN

Dr. L. Stenflo, Univ. of UMEA, SWEDEN

Libray. Royal Inst. of Technology, SWEDEN

Prol. H, Witheimson, Chalmers Univ, of Tech., SWEDEN

Centre Phys. Des Plasmas, Ecole Polytech. SWITZERLAND

Bibliotheek, Inst. Voor Plasma-Fysica, THE NETHERLANDS

Asst. Prof. Dr. S. Cakir, Mikdle East Tech. Univ., TURKEY

Dr. V.A. Glukhikh,Sci. Res. Inst. Electrophys.l Apparatus, USSR

Dr, D.D. Ayutov, Siberian Branch of Academy of Sai., USSR

Dr. G.A. Eliseev, 1.V. Kurchatov Inst. USSA

Librarian, The Ukr.SSR Academy of Sciences, USSR

Dr. L.M. Kovrizhnykh, Inst. of General Physiøs, USSR

Kemforschungsanlage GmbH, Zentralbibliothek, W. GERMANY

Bibliothek, Inst. For Plasmatorschung. W. GERMANY

Prol. K. Schindler, Ruhr-Universitát Bochum, W. GERMANY

Dr. F. Wagner, (ASDEX), Max-Planck-Institut, W. GERMANY

Librarian, Max-Planck-Institut, W. GERMANY 